\title{
Mapping leaf chlorophyll content from Sentinel-2 and RapidEye data in spruce stands using the invertible forest reflectance model
}

\author{
Roshanak Darvishzadeh $^{\mathrm{a}, *}$, Andrew Skidmore ${ }^{\mathrm{a}, \mathrm{b}}$, Haidi Abdullah ${ }^{\mathrm{a}}$, Elias Cherenet $^{\mathrm{c}}$, Abebe Ali $^{\mathrm{a}}$, \\ Tiejun Wang ${ }^{\mathrm{a}}$, Willem Nieuwenhuis ${ }^{\mathrm{a}}$, Marco Heurich ${ }^{\mathrm{d}, \mathrm{e}}$, Anton Vrieling ${ }^{\mathrm{a}}$, Brian O’Connor ${ }^{\mathrm{f}}$, \\ Marc Paganini ${ }^{g}$ \\ ${ }^{a}$ Faculty of Geo-Information Science and Earth Observation (ITC), University of Twente, P.O. Box 217, 7500 AE, Enschede, the Netherlands \\ ${ }^{\mathrm{b}}$ Department of Environmental Science, Macquarie University, NSW, 2106, Australia \\ ${ }^{\mathrm{c}}$ Haramaya University, Department of Geo-information Science, P.O. box 138, Dire Dawa, Ethiopia \\ ${ }^{\mathrm{d}}$ Department of Visitor Management and National Park Monitoring, Bavarian Forest National Park, 94481, Grafenau, Germany \\ ${ }^{\mathrm{e}}$ Chair of Wildlife Ecology and Wildlife Management, University of Freiburg, Tennenbacher Straße 4, Germany \\ ${ }^{\mathrm{f}}$ UN Environment World Conservation Monitoring Centre, 219 Huntingdon Road, Cambridge, CB3 ODL, UK \\ ${ }^{\mathrm{g}}$ European Space Agency - ESRIN, Via Galileo Galilei, Casella Postale 64, 00044, Frascati, RM, Italy
}

\section{A R T I C L E I N F O}

\section{Keywords:}

INFORM

RapidEye

Sentinel-2

Red edge

Lookup table

Leaf chlorophyll content

Norway spruce

\begin{abstract}
A B S T R A C T
Leaf chlorophyll plays an essential role in controlling photosynthesis, physiological activities and forest health. In this study, the performance of Sentinel-2 and RapidEye satellite data and the Invertible Forest Reflectance Model (INFORM) radiative transfer model (RTM) for retrieving and mapping of leaf chlorophyll content in the Norway spruce (Picea abies) stands of a temperate forest was evaluated. Biochemical properties of leaf samples as well as stand structural characteristics were collected in two subsequent field campaigns during July 2015 and 2016 in the Bavarian Forest National Park (BFNP), Germany, parallel with the timing of the RapidEye and Sentinel-2 images. Leaf chlorophyll was measured both destructively and nondestructively using wet chemical spectrophotometry analysis and a hand-held chlorophyll content meter. The INFORM was utilised in the forward mode to generate two lookup tables (LUTs) in the spectral band settings of RapidEye and Sentinel-2 data using information obtained from the field campaigns. Before generating the LUTs, the sensitivity of the model input parameters to the spectral data from RapidEye and Sentinel-2 were examined. The canopy reflectance of the studied plots were obtained from the satellite images and used as input for the inversion of LUTs. The coefficient of determination $\left(\mathrm{R}^{2}\right)$, root mean square errors (RMSE), and the normalised root mean square errors (NRMSE), between the retrieved and measured leaf chlorophyll, were then used to examine the attained results from RapidEye and Sentinel-2 data, respectively. The use of multiple solutions and spectral subsets for the inversion process were further investigated to enhance the retrieval accuracy of foliar chlorophyll. The result of the sensitivity analysis demonstrated that the simulated canopy reflectance of Sentinel-2 is sensitive to the alternation of all INFORM input parameters, while the simulated canopy reflectance from RapidEye did not show sensitivity to leaf water content variations. In general, there was agreement between the simulated and measured reflectance spectra from RapidEye and Sentinel-2, particularly in the visible and red-edge regions. However, examining the average absolute error from the simulated and measured reflectance revealed a large discrepancy in spectral bands around the near-infrared shoulder. The relationship between retrieved and measured leaf chlorophyll content from the Sentinel-2 data had a higher coefficient of determination with a higher NRMSE (NRMSE $=0.36 \mu \mathrm{g} / \mathrm{cm}^{2}, \mathrm{R}^{2}=0.45$ ) compared to those obtained using the RapidEye data (NRMSE $=0.31 \mu \mathrm{g}$ / $\mathrm{cm}^{2}$ and $\mathrm{R}^{2}=0.39$ ). Using the mean of the ten best solutions (retrieved chlorophyll) the retrieval error for both Sentinel-2 and RapidEye data decreased (NRMSE $=0.34$, NRMSE $=0.26$, respectively), as compared to only selecting the single best solution. When the Sentinel-2 red edge bands were used as the spectral subset, the retrieval error of leaf chlorophyll decreased indicating the importance of red edge, as well as properly located spectral bands, for leaf chlorophyll estimation. The chlorophyll maps produced by the inversion of the two LUTs effectively represented the variation of foliar chlorophyll in BFNP and confirmed our earlier findings on the observed stress pattern caused by insect infestation. Our findings emphasise the importance of multispectral
\end{abstract}

\footnotetext{
* Corresponding author.

E-mail address: r.darvish@utwente.nl (R. Darvishzadeh).
} 
satellites which benefits from red edge spectral bands such as Sentinel-2 as well as RapidEye for regional mapping of vegetation foliar properties, particularly, chlorophyll using RTMs such as INFORM.

\section{Introduction}

Biochemical parameters of plants are mainly controlling their overall photosynthetic and physiological activities (Cornelissen et al., 2003). The most critical leaf biochemical properties are chlorophyll pigments which largely affect the photosynthetic activities (Clevers and Kooistra, 2012; Cracknell et al., 2009; Gitelson et al., 2006; Inoue et al., 2016). Pigments of chlorophyll are in the form of chlorophyll $a$ and $b$, and each has distinct spectral absorption properties (Lichtenthaler and Buschmann, 2001). Both forms of chlorophyll pigments are valuable for plants' energy conversion. The total leaf chlorophyll content (mass per unit leaf area) is predominantly responsible for any photosynthesic activity in the leaf and has a major role in capturing the energy and adaptation process (Gitelson et al., 2006; Sims and Gamon, 2002). Because of its role in photosynthesis, leaf chlorophyll is an essential indicator of growth status and nutritional stress and is commonly used to evaluate stress, infestation or diseases, and heavy metal pollution in plants (Abdullah et al., 2018a; Cui and Zhou, 2017). Hence when used as a proxy for leaf photosynthetic aptitude, chlorophyll regulates the forest carbon exchange, which is a critical factor in understanding ecosystem response to climate change (Croft et al., 2017, 2015; Sievering et al., 2000).

Typically, ecologists use leaf chlorophyll content to study interaction between the ecosystem and biotic community, for example, to assess plant health status associated with disease or any environmental stressor (Garnier et al., 2007), gross primary productivity and ecosystem productivity (Gitelson et al., 2006; Lavorel et al., 2011; Orwin et al., 2010). Furthermore, previous studies also highlighted the role of chlorophyll pigments for habitat quality assessment and tree species identification (Castro-Esau et al., 2006; Delegido et al., 2014), estimation of crop net primary productivity and precision farming (Haboudane et al., 2002; Navarro-Cerrilloa et al., 2014) Foliar chlorophyll is acknowledged as one of the "essential biodiversity variables" which can be monitored through remote sensing (Skidmore et al., 2015).

Several in situ/laboratory (in situ) methods and remote sensing approaches for measuring/ estimating leaf chlorophyll content have been developed. Traditionally, wet chemical analysis is performed in laboratories to determine the foliar chlorophyll content of plants (Lichtenthaler, 1987; Lichtenthaler and Buschmann, 2001). In this method, fresh leaf samples are collected from the field and analysed in the laboratory (Brix, 1987). This method, though is the most accurate method for determining chlorophyll content in leaves, is destructive, and costly (Cortazar et al.,2015) hence applicable for minimal spatial coverage and not suitable for large-scale assessments. Contrary to the in situ based chlorophyll estimation, remote sensing based methods are efficient, non-destructive and enable assessments of larger temporal and spatial coverage (Homolová et al., 2013). Likewise, in the last decades, remote sensing data has been broadly used for chlorophyll estimation (Hernández-Clemente et al., 2012; Kokaly et al.,2009).

Remote sensing measurements from vegetation canopies, through their unique spectral signature, can provide valuable information about different vegetation parameters (Liang, 2004). Various spectral regions from visible to thermal infrared are recognized as useful for studying various vegetation traits at leaf and canopy levels (Ali et al., 2017a; Atzberger et al., 2013; Kokaly et al., 2009; Mirzaie et al., 2014; Neinavaz et al., 2017; Rivera et al., 2014; Ullah, 2013; Yoder and Pettigrew-Crosby, 1995; Zhu et al., 2017). Estimation of plant traits utilising remote sensing data requires a model to allow data interpretation and to explain the relationship of spectral data with the vegetation traits. Over the last three decades, several methods for retrieval of plant traits have been developed, but only a few have reached an operational phase. A comprehensive review of these retrieval methods has been given in Verrelst et al. (2015). Typically remote sensing approaches for estimating plant traits consist of physically based (deductive) and statistical (inductive) models (Skidmore, 2002), each having pros and cons. The physical approach to estimating vegetation variables implicates the use of radiative transfer models (RTMs) (or radiometric/spectral data-driven, (Baret and Buis, 2008)). The robustness and transferability of RTMs in comparison to statistical models makes them a preferable solution (Darvishzadeh et al., 2008; Demarez and Gastellu-Etchegorry, 2000). These models explain the spectral variations of plants through leaf, canopy, and background soil characteristics together with atmosphere and observation geometry based on physical laws (Liang, 2004; Verhoef, 1984). However, in order to use the RTMs for retrieving plant traits from remote sensing data, they must be invertible (Kimes et al., 2000). Various canopy RTMs have been developed from one-dimensional turbid medium to more complex three-dimensional ray tracing models (Widlowski et al., 2015). Among the existing RTMs, the Invertible Forest Reflectance Model (INFORM) (Atzberger, 2000), offers a trade-off between the realism of simulation of the forest canopy and inversion feasibility. Several RTM inversion algorithms have been established (Verrelst et al., 2015), while among them the commonly used method is the lookup table (LUT) approach (Atzberger et al., 2013; Knyazikhin et al., 1998). The LUT approach is efficient for regional mapping of vegetation parameters (Schlerf and Atzberger, 2012) and is recommended for handling complex models (Kimes et al., 2000).

The spectral bands from the visible and red edge region (400-750 nm) show high sensitivity to foliar chlorophyll (Curran, 1989; Dawson et al., 1999). Numerous studies have confirmed the usefulness of hyperspectral remote sensing measurements for leaf chlorophyll estimation (Darvishzadeh et al., 2008; Gitelson et al., 1996; Haboudane et al., 2002; Inoue et al., 2016; Jiao et al., 2014; Liang et al., 2016; Schlerf et al., 2010; Sun et al., 2018; Zarco-Tejada et al., 2002). Whereas broadband multispectral satellites are more regularly available and are also relatively less costly, few studies have examined the data from multispectral satellites for estimating leaf chlorophyll (Croft et al., 2015; Darvishzadeh et al., 2012; Houborg et al., 2015; PastorGuzman et al., 2015) with various degree of success. The advances in remote sensing and availability of high-resolution satellites that provide spectral information from the red edge spectral region (such as RapidEye and Sentinel-2) has offered new opportunities to improve mapping and estimation of leaf chlorophyll over large spatial extents. Recently several studies have successfully investigated the estimation of leaf chlorophyll in crops using data from these new sensors (Clevers and Gitelson, 2013; Clevers et al., 2017; Dahms et al., 2016; Houborg and McCabe, 2016; Kooistra and Clevers, 2016; Shang et al., 2015). However, to our knowledge, assessing the potential of these sensors for estimation of leaf biochemical variables, especially leaf chlorophyll content, in forest ecosystems and for spruce stands, which are highly vulnerable in Europe for infestation by insect pest is rarely studied.

Therefore, this study aimed to evaluate the performance of RapidEye and Sentinel-2 spectral data, through inversion of INFORM for retrieving foliar chlorophyll content in spruce stands. The INFORM model has been used successfully for retrieving other plant traits from hyperspectral and Landsat 8 data (Ali et al., 2016c; Schlerf and Atzberger, 2012, 2006; Wang et al., 2018; Yuan et al., 2015). However, to our knowledge, its potential to retrieve leaf chlorophyll content has not been investigated. Hence, our specific objectives in this study were: 
1) to explore the feasibility of INFORM for leaf chlorophyll content retrieval from RapidEye and Sentinel-2 spectral data, and 2) to map the spatial variation of leaf chlorophyll content in the spruce stands of a temperate heterogonous forest using RapidEye and Sentinel-2 data. The study benefits from two field data sets which were collected during summer 2015 and 2016 in spruce stands of the Bavaria Forest National Park (BFNP), Germany.

\section{Materials and methods}

\subsection{Study site and field data collection}

The Bavarian Forest National Park in Germany (BFNP) has an approximate area of $240 \mathrm{~km}^{2}$. It is situated in south-eastern Germany, at centre coordinates of $13^{\circ} 12^{\prime} 9^{\prime \prime} \mathrm{E}$ (longitude) and $49^{\circ} 3^{\prime} 19^{\prime \prime} \mathrm{N}$ (latitude) bordering the Czech Republic. The elevation of the BFNP varies between $600 \mathrm{~m}-1453 \mathrm{~m}$. The national park is alienated based on three ecological zones: highlands, hillsides, and valleys (Heurich et al., 2010). Around $90 \%$ of the trees in the highlands are Norway spruce (Picea abies (L.) Karst), 2\% are beech (Fagus sylvatica L.), and the rest (about $8 \%$ ) are other broad-leaf trees. On the hillsides, around $58 \%$ of trees are Norway spruce, and the remaining consists of European silver fir and beech mixture, while $83 \%$ of trees in the valleys, are Norway spruce, and the remaining is a mixture of different species (Cailleret et al., 2014). The dominant Norway spruce forest is known for having a long history of bark beetle infestations (Ips typographus), which caused a massive dieoff of about 6000 ha of spruce forest in BFNP (Lausch et al., 2013).

Given the majority of the spruce stands in the forest, the time and cost constraints, we randomly selected 30 and 50 sample plots of $30 \mathrm{~m} \times 30 \mathrm{~m}$ for the year 2015 and 2016, respectively (Fig. 1) in the spruce strata. Field campaigns were performed in early July, and to understand the variation of leaf chlorophyll through the two subsequent years, the sampled plots from 2015 and those of 2016 had about one-third of overlaps. The Differential Global Positioning System (DGPS) Leica GPS 1200 (Leica Geosystems AG, Heerbrugg, Switzerland) with an accuracy of less than $1 \mathrm{~m}$ (after post-processing) was used to measure the centre coordinate of each plot. In each sample plot different biophysical parameters and stand characteristics such as height (H), average leaf angle (ALA), canopy closure (CC), leaf area index (LAI), canopy diameter (CD), and stem density (SD) were recorded. The stand height $(\mathrm{H}), \mathrm{CC}$ and $\mathrm{CD}$ were obtained by calculating the average height, canopy closure and crown diameter of five representative trees selected in each plot. The tree height was measured using a Nikon Forestry 550 laser rangefinder, the CC was measured using the Convex Spherical Crown Densitometer, and the CD for each tree was obtained by calculating the average of two perpendicular projected distances. The sum of trees per hectare was considered as the stem density (SD). The LAI and ALA for each plot were measured using Li-Cor LAI-2200 canopy analyser (LI-COR, 1992). For each plot, one reference (above canopy) reading was performed in the nearest open field, and five below canopy measurements were taken inside each plot. During the LAI measurements care was taken to have constant illumination conditions for the above and below canopy readings. The summary statistics of the measured forest parameters obtained from the field campaigns are presented in Table 1.

To obtain the leaf biochemical parameters, five representative trees were measured within each plot. As such from the upper canopy of each tree (exposed to sunlight), an average of two to three branches were collected (Abdullah et al., 2018b) using an Excalibur Matrix 310 crossbow which was used to shoot at a branch with sunlit leaves with an arrow coupled to a fishing line (Ali et al., 2016a). Then, a hand-held chlorophyll content meter CCM-300 was employed to measure the leaf chlorophyll of the sampled branches. Next, the leaf samples were directly separated from the collected branches and were retained in ziplocked bags, while sheltered with wet pulp paper and then carried to the laboratory using ice packs with a portable cooling box to preserve

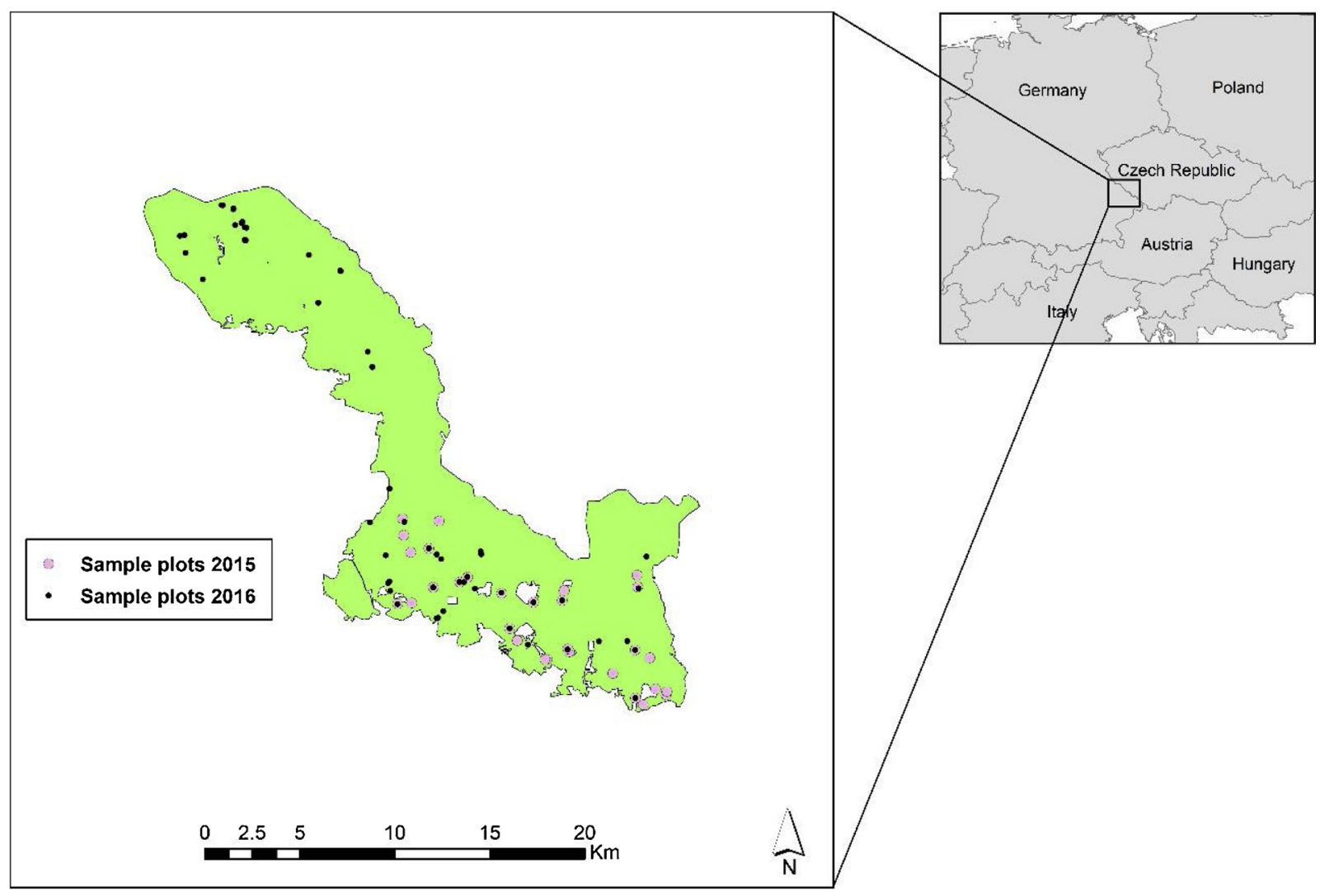

Fig. 1. Distribution of samples collected in summer 2015 and 2016 in the Bavarian Forest National Park, Germany. 
Table 1

Summary statistics of the measured forest structural and biochemical variables from the two field campaigns $(n=70$, summer $2015(n=30)$ and 2016 $(n=50)) . C_{m}$ : leaf mass, $C_{w}$ : leaf water content, $H$ : stand height, CC: canopy closure, ALA: average leaf angle, the CD: canopy diameter, LAI: leaf area index, and SD: the stem density.

\begin{tabular}{lllllllll}
\hline $\begin{array}{l}\text { Summary } \\
(\mathrm{n}=70)\end{array}$ & $\begin{array}{l}\mathrm{C}_{\mathrm{m}} \\
\left(\mathrm{g} \mathrm{cm}^{-2}\right)\end{array}$ & $\begin{array}{l}\mathrm{C}_{\mathrm{w}} \\
\left(\mathrm{g} \mathrm{cm} \mathrm{cm}^{-2}\right)\end{array}$ & $\begin{array}{l}\mathrm{H} \\
(\mathrm{m})\end{array}$ & $\begin{array}{l}\mathrm{CC} \\
(\%)\end{array}$ & $\begin{array}{l}\text { ALA } \\
(\text { degree })\end{array}$ & $\begin{array}{l}\mathrm{CD} \\
(\mathrm{m})\end{array}$ & $\begin{array}{l}\mathrm{LAI} \\
\left(\mathrm{m}^{2}\right. \\
\left.\mathrm{m}^{-2}\right)\end{array}$ & $\begin{array}{l}\mathrm{SD} \\
\left(\mathrm{ha}^{-1}\right)\end{array}$ \\
\hline Minimum & 0.010 & 0.004 & 14 & 48 & 39.8 & 1.5 & 0.5 & 170 \\
Maximum & 0.029 & 0.033 & 29 & 87 & 65.4 & 8 & 5.9 & 5000 \\
Mean & 0.016 & 0.016 & 19.9 & 71 & 51.2 & 4.1 & 3.4 & 290 \\
Std.dev & 0.003 & 0.005 & 3.6 & 10 & 7.4 & 1.5 & 1.1 & 90 \\
\hline
\end{tabular}

them fresh and to impede probable alterations in biochemical characteristics.

In the laboratory, the surface area of the leaf samples was measured using AM-350 leaf area meter, and their chlorophyll content was obtained following Lichtenthaler's (1987) method. These measurements were also used to calibrate/validate the recorded values from CCM-300 in 2015 and 2016. For this, a portion ( $3 \mathrm{~g}$ ) of fresh leaf samples were ground with acetone to extract the green pigments, and a double beam spectrophotometer was used to read the chlorophyll $a$ and $b$ absorption coefficients at sensitive wavelengths of $661.8 \mathrm{~nm}$ and $644.8 \mathrm{~nm}$, respectively. The total leaf chlorophyll concentration was then calculated following the Lichtenthaler and Buschmann (2001) study and was converted into area-based chlorophyll content $\left(\mu \mathrm{g} / \mathrm{cm}^{2}\right)$ using the leaf sample surface area. Further, leaf water content $\left(\mathrm{C}_{\mathrm{w}}\right)$ and leaf mass $\left(\mathrm{C}_{\mathrm{m}}\right)$ were measured using the oven dried leaves and their corresponding leaf areas. To obtain the leaf properties at the plot level, for each plot, the measured leaf biochemical parameters (leaf chlorophyll, leaf water content and leaf mass) from the selected representative trees were averaged (Tables 1 and 3 ).

\subsection{Satellite data}

Cloud-free high-resolution multispectral satellite images were acquired parallel to the time of the field campaigns, i.e. on 2 July 2015 for RapidEye and 8 July 2016 for Sentinel-2. RapidEye is a constellation of five satellites providing high-resolution multispectral imagery in five spectral bands (blue, green, red, red-edge and near infrared). Two RapidEye L2A images covering the southern part of the park were systematically geo-corrected and orthorectified at a spatial resolution of $5 \mathrm{~m}$ (Planet, 2016). To obtain the top of canopy (TOC) reflectance data, ATCOR-2 was used for atmospheric and topographic correction (Richter

(Sentinel-2)

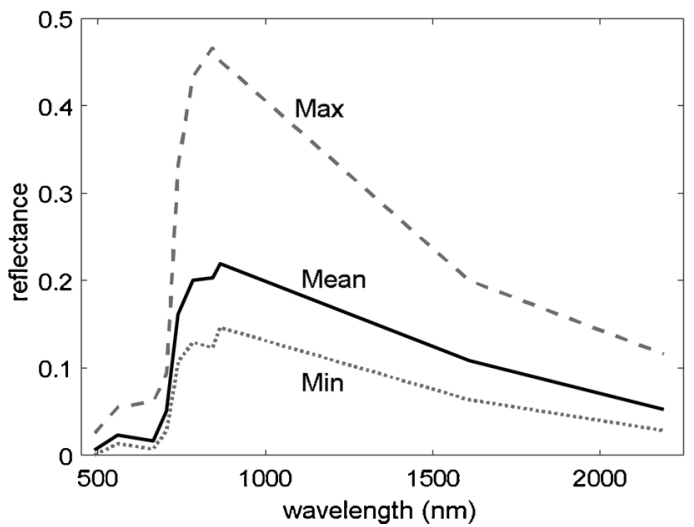

and Schläpfer, 2018). The mean spectral reflectance for each sample plot in 2015 was then extracted by considering a kernel size of 5*5 pixels (i.e. $25 \mathrm{mx} 25 \mathrm{~m}$ ), hereafter referred to as RapidEye measured reflectance, and was utilised for further analysis.

The standard Sentinel-2 Level-1C product, with UTM/WGS84 projection in Top of Atmosphere (TOA) reflectance, was obtained from the European Space Agency's (ESA) Copernicus Open Access Hub (https:// scihub.copernicus.eu/). To obtain the Level-2 A TOC reflectance data, the image was atmospherically corrected using the Sen2Cor processor. Sentinel-2 offers spectral data in 13 bands from 443 to $2190 \mathrm{~nm}$ with three red edge bands with a central wavelength at $705 \mathrm{~nm}, 740 \mathrm{~nm}$, $783 \mathrm{~nm}$, respectively. The TOC data was used to retrieve the reflectance spectra of the plots sampled in 2016. The centre coordinates of the sample plots were overlaid on the Sentinel-2 image $(20 \mathrm{~m})$, and the reflectance of the corresponding pixels was extracted for each sample plot. The mean reflectance of all plots for 2015 (RapidEye) and 2016 (Sentinel 2) are presented in Fig. 2. For this study, the spectral bands with the $60 \mathrm{~m}$ spatial resolution, which are designed for coastal, water vapour and cirrus studies, were not utilised.

\subsection{The INFORM radiative transfer model}

The Invertible Forest Reflectance Model (INFORM) (Atzberger, 2000) is a hybrid model that integrates the Forest Light Interaction Model (FLIM) (Rosema et al., 1992), Scattering by Arbitrary Inclined Leaves (SAILH) (Verhoef, 1985, 1984), and PROSPECT (Fourty et al., 1996; Jacquemoud et al., 1996; Jacquemoud and Baret, 1990) to simulate the bidirectional reflectance of forest canopies. INFORM considers the one-dimensional turbid medium radiative-transfer within the crowns and the three-dimensional characteristics such as clumping of the leaves and shadows of the crowns (Atzberger, 2000; Schlerf and Atzberger, 2012, 2006). The model offers a compromise concerning the feasibility of inversion and exhaustive characterisation of the canopy structure (Schlerf and Atzberger, 2006). The capacity and suitability of INFORM for retrieving forest structural and biochemical variables such as fAPAR, LAI, leaf dry matter, leaf water content, specific leaf area, leaf and canopy nitrogen content has been demonstrated in both broadleaf and conifer stands with varying levels of success (Ali et al., 2016c; Schlerf and Atzberger, 2012, 2006; Wang et al., 2018; Yang et al., 2011; Yuan et al., 2015; Zhu et al., 2019). However, the model has not previously been used for retrieving leaf chlorophyll, in particular using high-resolution multispectral data.

In addition to background soil reflectance, the model has 15 input parameters corresponding to coupled PROSPECT, SAILH and the FLIM models (Table 2). Leaf level parameters such as leaf structure

\section{(RapidEye)}

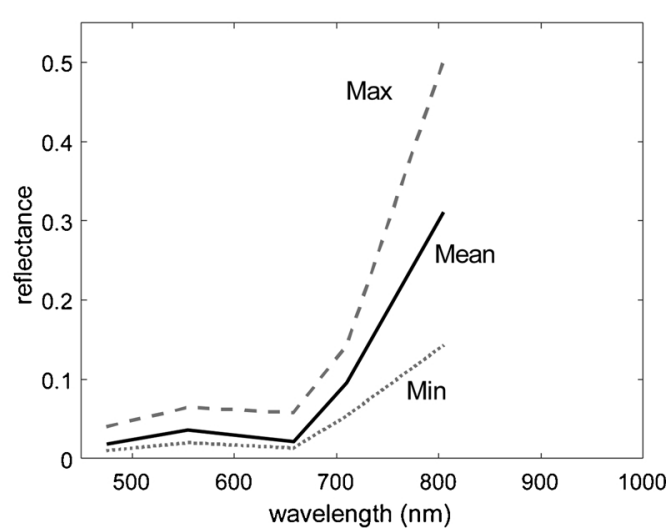

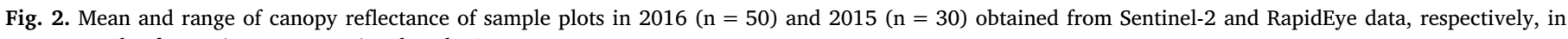
spruce stands of Bavarian Forest National Park, Germany. 
Table 2

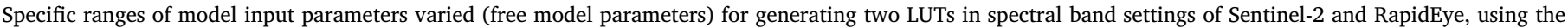
forward calculation of the INFORM. Parameters values are drawn randomly within these specific ranges.

\begin{tabular}{|c|c|c|c|c|}
\hline Input paramtere & Abbervation in model & Unit & Minimum value & Maximum value \\
\hline Crown diameter ${ }^{*}$ & $\mathrm{CD}$ & $\mathrm{m}$ & 1 & 10 \\
\hline Stem density" & SD & $\mathrm{ha}^{-1}$ & 160 & 5500 \\
\hline Stand height" & $\mathrm{H}$ & $\mathrm{m}$ & 10 & 35 \\
\hline Single trees LAI & $\mathrm{LAI}_{\mathrm{s}}$ & $\mathrm{m}^{2} \cdot \mathrm{m}^{-2}$ & 1 & 7 \\
\hline LAI understory ${ }^{*}$ & $\mathrm{LAI}_{\mathrm{u}}$ & $\mathrm{m}^{2} \cdot \mathrm{m}^{-2}$ & 0.2 & 0.8 \\
\hline Average leaf angle & ALA & degree & 40 & 75 \\
\hline Leaf structure parameter & $\mathrm{N}$ & No dimension & 1 & 2.5 \\
\hline Chlorophyll content" & $\mathrm{Cab}$ & $\mu \mathrm{g} \cdot \mathrm{cm}^{-2}$ & 20 & 60 \\
\hline Leaf dry matter content & $\mathrm{C}_{\mathrm{m}}$ & $\mathrm{g} \cdot \mathrm{cm}^{-2}$ & 0.008 & 0.03 \\
\hline Equivalent water thickness & $\mathrm{C}_{\mathrm{w}}$ & $\mathrm{g} \mathrm{cm}^{-2}$ & 0.0035 & 0.035 \\
\hline Soil brightness parameter & scale & No dimension & 0.5 & 1.2 \\
\hline
\end{tabular}

* The ranges are designated based on the prior knowledge from the two field campaigns.

** The value was kept constant to its mean value (0.02) for generation of the RapidEye LUT.

Table 3

Summary statistics of leaf chlorophyll measurement using wet chemistry analysis in $2016(\mathrm{n}=50)$ and $2015(\mathrm{n}=30)$ in BFNP, Germany.

\begin{tabular}{lll}
\hline Basic statistics & $\begin{array}{l}\text { Chlorophyll }\left(\mathrm{ug} / \mathrm{cm}^{2}\right) 2016 \\
(\mathrm{n}=50)\end{array}$ & $\begin{array}{l}\text { Chlorophyll }\left(\mathrm{ug} / \mathrm{cm}^{2}\right) 2015 \\
(\mathrm{n}=30)\end{array}$ \\
\hline Minimum & 28.8 & 31.3 \\
Maximum & 53.8 & 53.1 \\
Mean & 37 & 40.9 \\
Standard dev. & 5.6 & 5.7 \\
\hline
\end{tabular}

parameter, chlorophyll content, leaf dry matter content, and leaf water content are used to simulate the leaf hemispherical transmittance and reflectance through PROSPECT. In addition to these leaf level parameters, INFORM requires several other variables explaining the canopy geometrical structure (single tree LAI; mean leaf inclination angle, crown diameter, stem density and stand height), background soil (understory vegetation, the brightness factor for the background soil reflectance), and observation related variables (relative azimuth angle, sensor viewing angle, solar zenith angle, and fraction of diffuse incoming solar radiation) to simulate the bidirectional reflectance of forest canopies. Because it is highly uncommon to find bare soil on the forest floor, the average reflectance spectra of the forest floor elements and understory vegetation which was measured by Ali et al. (2017b, 2016b) were utilised.

Of the existing 15 model input parameters, four parameters (solar zenith angle, relative azimuth angle, sensor viewing angle, and also the fraction of diffuse incoming solar radiation) were kept constant. Five hundred thousand $(500,000)$ sets were then generated randomly using uniform distributions for the other model input parameters, as proposed by le Maire et al. (2008) using the available ranges in the literature and prior information from the field campaigns (Tables 1 and 2). Such a parameterisation is expected to enhance the parameters retrievals in RTM modelling (Baret and Buis, 2008; Combal et al., 2002).

\subsubsection{Model sensitivity analysis}

The suitability of INFORM utilising hyperspectral data to study some parameters in forest ecosystems has been demonstrated earlier (Ali et al., 2016c; Schlerf and Atzberger, 2006; Wang et al., 2018). However, local sensitivity analysis (Bowyer et al., 2003) were additionally performed in this study to understand the impact of each model input parameter, in particular, leaf chlorophyll, on the simulated canopy reflectance of RapidEye and Sentinel-2, respectively, generated by the INFORM model. We examined the effect of each model input parameter on the corresponding spectral reflectance of RapidEye and Sentinel- 2 by varying each time one parameter value systematically and keeping the rest of the parameters at constant values. The model parameters that did not affect either RapidEye or Sentinel-2 simulated reflectance spectra were further fixed to constant values in the subsequent generation of LUTs.

\subsection{Parametrisation and the lookup table (LUT) inversion}

In contrast to other methods such as numerical optimisation and neural networks, LUT offers a modest approach to solve the inversion of a RTM (Houborg et al., 2009; Knyazikhin et al., 1998; Weiss et al., 2000). Utilising LUT would allow for a global search in the parameter space while resulting in a less unexpected mismatch between the modelled and measured spectra (Atzberger et al., 2015; Darvishzadeh et al., 2008; Schlerf and Atzberger, 2012, 2006). However, to obtain good retrieval accuracy for the investigated parameters, the size of LUT must be large (Atzberger et al., 2015; Combal et al., 2002; Tang et al., 2006).

To build two LUTs in the spectral band settings of RapidEye and Sentinel-2, the 500,000 parameter combinations that were randomly generated, were utilised with observation specific parameters from each spectral dataset of the two sensors in the forward calculation of the INFORM. This resulted in two simulated datasets (LUTs), which were then used in the inversion process of RapidEye and Sentinel-2 spectral datasets. The parameter ranges for the "free" model parameters were fixed using the prior information from the two field campaigns (Tables 1 and 3), in order to prevent a too wide parameter space (Darvishzadeh et al., 2011, 2008). The use of such prior information has facilitated to regularise the ill-posed problem of the inversion and has been the endorsed procedure in various studies (Atzberger et al., 2015; Combal et al., 2003; Darvishzadeh et al., 2008; Yang et al., 2011). In INFORM, LAI is presented by the LAI of single trees, therefore, the field measured LAI, and the canopy closure were used to obtain the LAI for single trees (i.e., LAIs = LAI/CC) (Schlerf and Atzberger, 2006). For the leaf structure parameter $(\mathrm{N})$, the recommended range by Ali et al. (2016a) for conifer needles, which was obtained by inverting the PROSPECT model, was utilised. The maximum and minimum values of these parameters are reported in Table 2. The value of the fraction of diffuse incoming solar radiation ( $s k y l)$ was fixed to 0.1 through all corresponding bands of the RapidEye and Sentinel-2 (Ali et al., 2017b; Atzberger et al., 2015; Darvishzadeh et al., 2011; Schlerf and Atzberger, 2006) as this parameter has a negligible effect on the reflectance of canopy (Clevers and Verhoef, 1991). Moreover, in each LUT the three parameters related to observation geometry were fixed based on the information obtained from metadata of the corresponding images. As such solar zenith angle $\left(26^{\circ}, 40^{\circ}\right)$, sensor viewing angle $\left(52^{\circ}, 5^{\circ}\right)$, and relative azimuth angle $\left(69^{\circ}, 100^{\circ}\right)$ were considered for the RapidEye and Sentinel-2 LUTs, respectively. It has been earlier identified that these parameters have insignificant effects on the INFORM simulated canopy reflectance (Ali et al., 2016b). For the soil reflectance, the average background reflectance, which was measured using an ASD field spectroradiometer 
from 385 samples of barks, lichens, litter and mosses from the forest floor (Ali et al., 2016c), was interpolated to spectral band settings of RapidEye and Sentinel-2 and used for the corresponding LUT generations. To explain the roughness and moisture variations in (soil) background reflectance, the soil brightness parameter 'scale' (Atzberger et al., 2003) was considered (Table 2).

The inverse problem for the canopy reflectance extracted from the RapidEye and Sentinel-2 images was solved considering the root mean square errors (RMSE) as the cost function for each simulated canopy reflectance spectra in the LUTs of the two sensors. As such the RMSE between the simulated reflectance spectra and the extracted reflectance from RapidEye and Sentinel-2 data was computed respectively, according to:

$R M S E=\sqrt{\frac{\sum_{k=1}^{n}(\text { pimage } \lambda-\rho L U T \lambda)^{2}}{n}}$

Where $\rho_{\text {image }}$ is the image-extracted reflectance of the sample plots, and $\rho_{\mathrm{LUT}}$ is the simulated reflectance in the LUT, $\lambda$ is the corresponding spectral band, and $\mathrm{n}$ is the number of spectral bands of RapidEye and Sentinel-2, respectively. The set of model input parameters related to a simulated reflectance from the LUT that most resembles the canopy reflectance of the plot extracted from the RapidEye and Sentinel-2 images, respectively (hence the smallest RMSE) is considered as the solution. Nevertheless, such a solution may not always be unique causing the so-called ill-posed problem. Therefore, to address this and to improve the estimated values of leaf chlorophyll content, besides the single solution with the smallest RMSE value the utilisation of the mean from the best 10, 50 and 100 solutions was examined. Further, a proper spectral band selection is recognised as a marginal approach to enhance the RTM inversion results (Atzberger et al., 2013; Lavergne et al., 2007; Meroni et al., 2004). Because RapidEye data has merely five spectral bands, only Sentinel-2 data was further explored for band subsetting. We investigated whether the leaf chlorophyll estimates from Sentinel-2 data through INFORM inversion could be improved by selecting spectral subsets. Three spectral subsets were considered by selecting a) the spectral bands with central wavelengths close to those from RapidEye, b) red edge spectral bands, and c) excluding spectral bands with high average absolute errors (AAE) between Sentinel-2 measured and simulated reflectance. More details on the calculation of AAE can be found in Darvishzadeh et al. (2011, 2008).

\subsection{Model validation and mapping}

The retrieved leaf chlorophyll content was validated using the laboratory measured leaf chlorophyll. The coefficient of determination $\left(\mathrm{R}^{2}\right)$, the root means square error (RMSE), and the normalised RMSE
(NRMSE, RMSE/range) (Atzberger, 1997; Darvishzadeh et al., 2008) between retrieved leaf chlorophyll and lab measured chlorophyll were used to compare retrieval accuracies. The leaf chlorophyll content of the spruce stands in the BFNP was then mapped using INFORM and the Sentinel-2 and RapidEye images. For this, the spruce class from the vegetation map obtained from the national park administration (Silveyra Gonzalez et al., 2018) was used to mask the Sentinel-2 and RapidEye data. The masked images were then used into the inversion process, and the predicted leaf chlorophyll maps using the best fitting spectra (minimum RMSE criterion) were retrieved.

\section{Results}

\subsection{Wet chemistry chlorophyll estimation}

The measured foliar chlorophyll content using wet chemical analysis is presented in Table 3. A strong correlation was observed between the field measured leaf chlorophyll using the CCM-300 and wet laboratory analysis $(r=0.83$, not shown). As can be observed from Table 3, the ranges of the measured foliar chlorophyll content in 2015 and 2016 were relatively close, though the observed range was slightly larger in 2016. These ranges are not far from those reported in earlier studies for the BFNP (Wang et al., 2015). The measured leaf chlorophyll from both years demonstrated similar variability and only slightly lower variation in 2015 (coefficient of variation $=0.14$ ) compared to those in 2016 (coefficient of variation $=0.15$ ).

\subsection{Sensitivity analysis of INFORM parameters}

Sensitivity analysis was performed for all INFORM model input parameters using RapidEye and Sentinel-2 spectral band settings. As was expected the simulated canopy reflectance of both sensors were primarily affected by all stand structural parameters (leaf area index (LAI), tree height (H), average leaf angle (ALA), canopy diameter (CD) and stem density (SD)) (not shown). Leaf chlorophyll content (Cab) exhibited a significant impact on the simulated canopy reflectance of RapidEye. Almost all spectral bands of this sensor (except the NIR band with a central wavelength of $805 \mathrm{~nm}$ ) demonstrated sensitivity to variation of leaf chlorophyll. Further, the variation of this parameter also affected the visible and red-edge spectral bands from Sentinel-2. Nonetheless, it was observed that the influence of Cab on red-edge band centred at 705 and $740 \mathrm{~nm}$ was stronger than on $783 \mathrm{~nm}$, which is closer to the NIR region (not shown). Moreover, the effect of leaf dry mass $\left(\mathrm{C}_{\mathrm{m}}\right)$, as a non-pigment leaf parameter, using the Sentinel-2 data was more pronounced in two regions of near-infrared (NIR) and shortwave infrared (SWIR) while the role of this parameter on the simulated

(Sentinel-2)

(RapidEye)
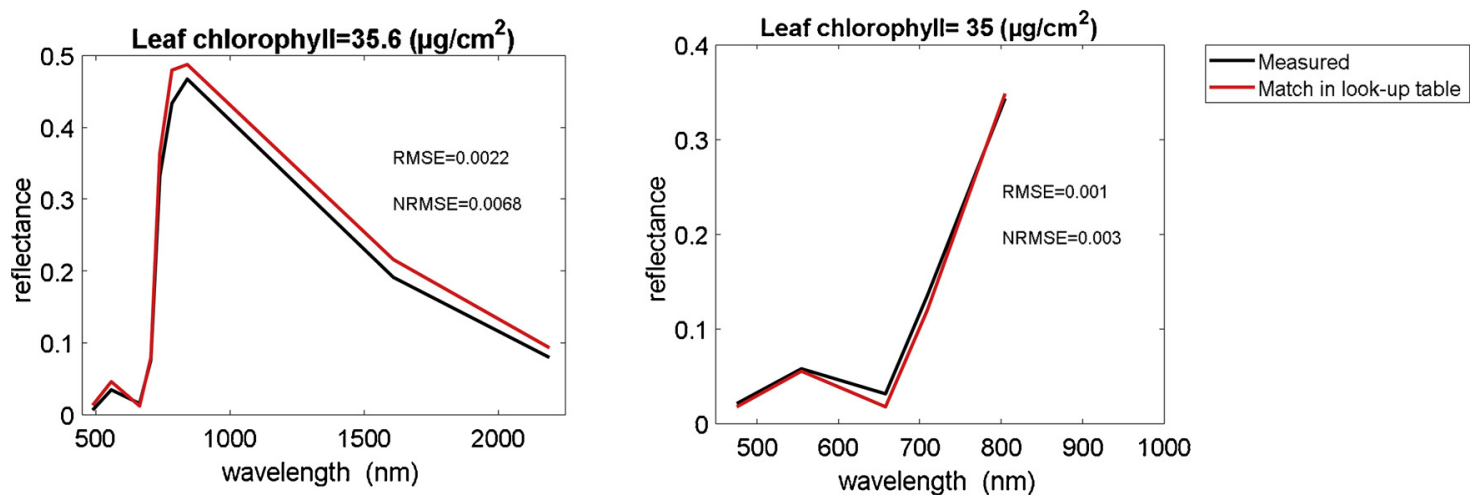

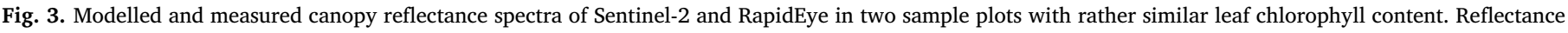
values are at distinct spectral wavelengths; lines are used to help the interpretation. 
canopy reflectance of RapidEye is more noticeable at Red-edge $(710 \mathrm{~nm})$ and NIR $(805 \mathrm{~nm})$ spectral bands (not shown). It was further observed that the leaf water has no effect on the simulated canopy reflectance spectra of RapidEye and the effect of this parameter can only be distinguished lightly in the NIR and mostly on SWIR spectral bands of Sentinel-2. Subsequently, leaf water content was fixed to a constant value $\left(C_{w}=0.02\right)$ for the RapidEye LUT and all the other parameters (leaf chlorophyll, leaf mass and all stand structural parameters were varied during the LUT generations for RapidEye and Sentinel-2.

\subsection{Inversions based on minimum RMSE criterion}

Both LUTs of RapidEye and Sentinel-2 were sorted based on the minimum RMSE measure (cost function), utilised to solve the inverse problem. The set of parameter values corresponding to the simulated canopy reflectance which provided the smallest RMSE, with a given canopy reflectance from the two sensors, was regarded as the solution. Fig. 3 illustrates the canopy reflectance spectra from RapidEye and Sentinel-2 and the so-called best-simulated canopy reflectance spectra from the LUTs calculated in this way for two plots with rather similar leaf chlorophyll values. As can be observed from Fig. 3, the modelled reflectance of Sentinel-2 and RapidEye using INFORM are somehow in agreement with the reflectance acquired from the corresponding images. However, for Sentinel_2 data larger discrepancies between the simulated and measured canopy reflectance data can be found in the NIR and shortwave infrared spectral bands.

A succinct analysis demonstrated that the dissimilarities between the modelled and measured canopy spectral reflectance from Sentinel-2 and RapidEye exhibit similar trends and particularly the visible and red edge spectral bands of the two sensors were simulated with somewhat similar average absolute errors (AAE) (Darvishzadeh et al., 2008). In Fig. 4, the AAEs between the Sentinel-2 and RapidEye measured and the best-fit spectra (with minimum RMSE between image and modelled canopy spectra) of the two datasets are demonstrated. As can be realised from the figure, the AAEs calculated for the data from the two sensors in the visible and start of the red edge regions are generally low and somehow corresponds to each other, though the infrared and the third red edge band of Sentinel-2 demonstrated relatively larger errors.

The variation of retrieved and measured foliar chlorophyll content using the minimum RMSE criterion for both sensors were further studied and are demonstrated in Fig. 5. In general, the observed variances between the estimated and measured leaf chlorophyll were more pronounced for plots with either high or low chlorophyll content in both 2015 and 2016 datasets. Using both Sentinel-2 or RapidEye datasets the dissimilarities between the estimated and measured leaf chlorophyll content were minimum for samples with values close to the means.

\subsection{Inversion using various solutions}

To further investigate the relation between the estimated and measured leaf chlorophyll content using the minimum RMSE criterion, we calculated their $\mathrm{R}^{2}$, RMSE and the NRMSE measures. The significance of using multiple solutions instead of only one solution corresponding to the minimum RMSE has been shown in our earlier study (Darvishzadeh et al., 2008). Therefore, we examined the best 10, 50, and 100 entries in the LUTs as the alternative solutions. The results of these analyses are presented in Table 4. As can be realised from the table, using the Sentinel-2 and RapidEye data and the mean of the first ten best solutions resulted in slightly higher retrieval accuracy for the leaf chlorophyll content (NRMSE $=0.34$ and 0.26), respectively, though the $\mathrm{R}^{2}$ values in both datasets decreased. When using the mean of 50 and 100 solutions, the retrieval accuracy (RMSE and NRMSE) started to deteriorate for both sensors.

The relationships between retrieved and measured leaf chlorophyll utilising the best ten solutions are demonstrated in Fig. 6. As can be seen from the scatter plots, in general, retrieved and measured leaf chlorophyll content had reasonable relationships. Leaf chlorophyll estimated using the Sentinel-2 data had a higher coefficient of determination $\left(\mathrm{R}^{2}=0.39\right)$ and larger error (NRMSE $\left.=0.34\right)$ with the measured chlorophyll in 2016.

We further examined whether the $\mathrm{R}^{2}$ and NRMSE of different solutions are significantly different. The result of one-way ANOVA (analysis of variance) showed that the mean $\mathrm{R}^{2}$ and NRMSE from different solutions for the two datasets had no significant differences ( $p>0.05$ ).

\subsection{Inversion results using spectral subsets from Sentinel-2}

Three subsets from Sentinel-2 data were considered for further analysis. The role of spectral subsets from Sentinel-2 data for the retrieval of leaf chlorophyll was further examined using $\mathrm{R}^{2}$, RMSE and the NRMSE between the measured and retrieved leaf chlorophyll. First, the spectral bands which had an AAE greater than 0.02 were considered as the bands with large errors (Darvishzadeh et al., 2008) (see Fig. 4). These bands only were present in Sentinel-2 $(783 \mathrm{~nm}, 842 \mathrm{~nm}$ and $865 \mathrm{~nm}$ ) while for RapidEye all bands had an AAE smaller than 0.02. Consequently, the inversion of Sentinel-2 LUT was performed excluding these wavelengths (subset A). Next, spectral bands in Sentinel-2 with central wavelengths similar (as close as possible) to those from RapidEye were selected $(490 \mathrm{~nm}, 560 \mathrm{~nm}, 665 \mathrm{~nm}, 705 \mathrm{~nm}$, and $783 \mathrm{~nm}$ ) and used as input for the inversion of LUT of Sentinel-2 (subset B). Finally, only the red-edge bands $(705 \mathrm{~nm}, 740 \mathrm{~nm}, 783 \mathrm{~nm})$ were chosen and again used for the inversion of Sentinel-2' LUT (subset C). The results are presented in Table 5 . As can be observed from the table utilising the first two subsets A and B from Sentinel-2 spectral data mainly decreased the retrieved accuracy of leaf chlorophyll and did not result in any enhancements of foliar chlorophyll estimation. However, when the spectral subset $C$ was used the retrieval error was slightly improved (NRMSE $=0.33$ ).

\subsection{Mapping leaf chlorophyll in Bavarian Forest National Park}

Foliar chlorophyll was mapped in the national park using the Sentinel-2 and RapidEye data. For this, the spruce area was extracted from the existing habitat map of the national park and used to mask out the non-spruce area from the Sentinel-2 and RapidEye images. Due to the presence of clouds for a small part of the Sentinel-2 image, a mask was applied to remove clouds from this image. The masked Sentinel-2

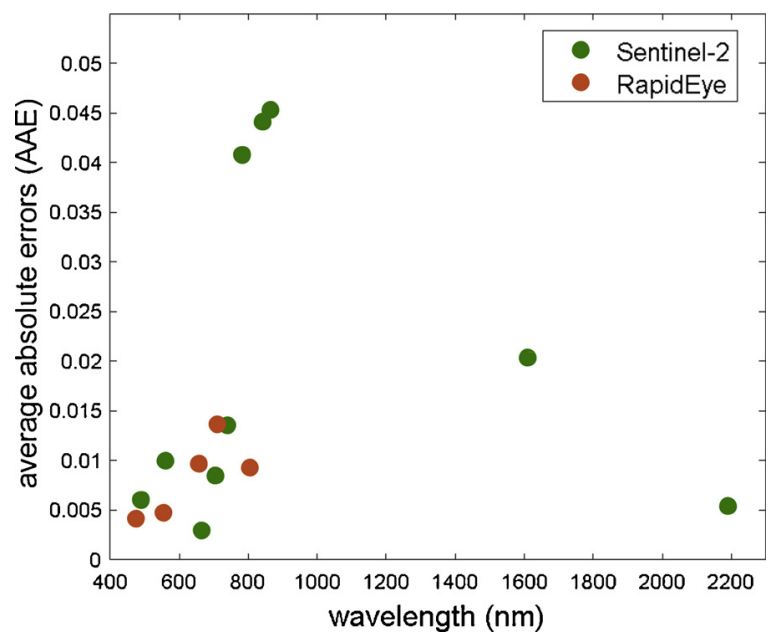

Fig. 4. The average absolute errors (AAEs) calculated between Sentinel-2 and RapidEye measured reflectance and their corresponding best-fit reflectance spectra. The AAE has been computed from the 30 and 50 image reflectance of RapidEye and Sentinel-2 and the corresponding best fitting reflectance from their LUTs, respectively. The AAE units are reflectance. 

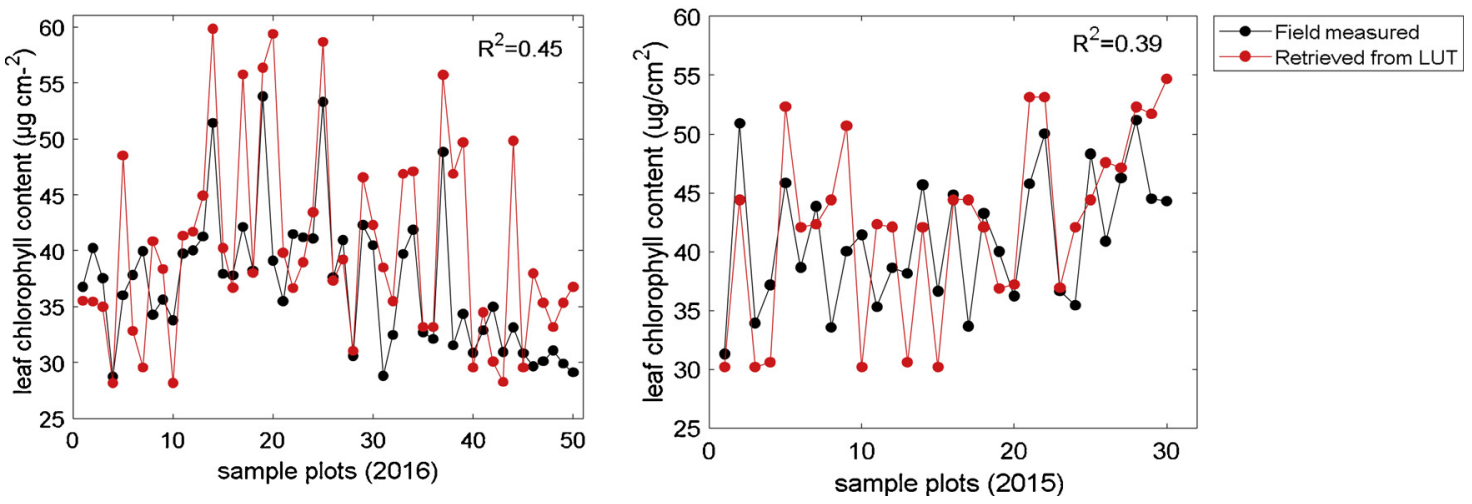

Fig. 5. Measured and modelled foliar chlorophyll using LUT inversion and Sentinel-2 and RapidEye for different sample plots in 2016 and 2015 , respectively.

Table 4

$\mathrm{R}^{2}$, RMSE and NRMSE between measured and retrieved foliar chlorophyll content $\left(\mu \mathrm{g} \mathrm{cm}^{-2}\right)$ in BFNP for $2015(\mathrm{n}=30)$ and $2016(\mathrm{n}=50)$ using RapidEye and Sentinel-2 data, respectively. The estimation of leaf chlorophyll is investigated based on the minimum cost function criteria "best fitting spectra", as well as mean of the first 10,50 and 100 solutions.

\begin{tabular}{|c|c|c|c|c|c|c|}
\hline \multirow[t]{2}{*}{ Solution } & \multicolumn{3}{|c|}{ Sentinel-2 $(n=50)$} & \multicolumn{3}{|c|}{ RapidEye $(\mathrm{n}=30$ ) } \\
\hline & $\mathrm{R}^{2}$ & RMSE & NRMSE & $\mathrm{R}^{2}$ & RMSE & NRMSE \\
\hline Best fitting spectra & 0.45 & 8.9 & 0.36 & 0.39 & 6.18 & 0.31 \\
\hline Mean of first 10 & 0.39 & 8.6 & 0.34 & 0.36 & 5.22 & 0.26 \\
\hline Mean of first 50 & 0.37 & 9.46 & 0.37 & 0.30 & 5.44 & 0.27 \\
\hline Mean of first 100 & 0.35 & 10.23 & 0.41 & 0.32 & 5.36 & 0.27 \\
\hline
\end{tabular}

and RapidEye images were then used as inputs to the inversion routines to produce the corresponding chlorophyll maps using the minimum RMSE criteria (best fitting spectra). These maps are illustrated in Fig. 7. The observed means of both maps were in agreements to the means of measured samples from the field campaigns (Table 3). As Fig. 7 demonstrate the spatial distribution of foliar chlorophyll of the two maps are comparable and follow a similar pattern. However visual inspection

(Sentinel-2)

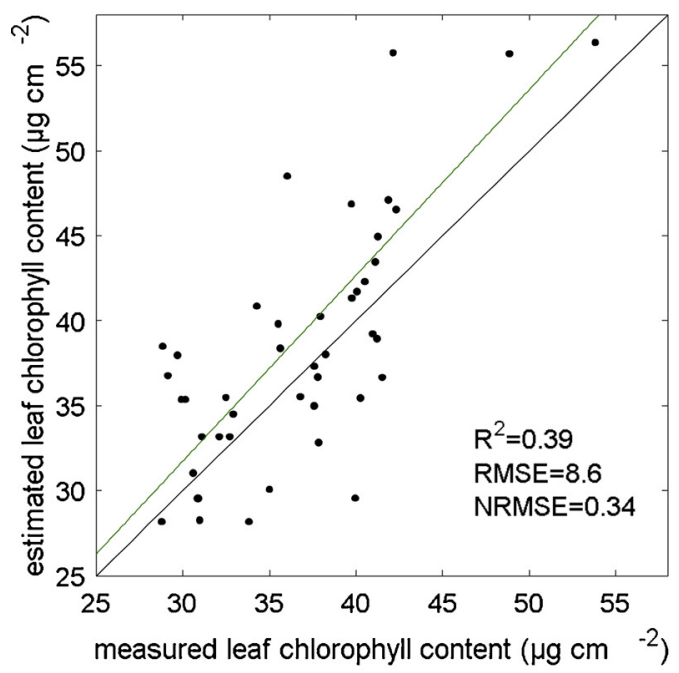

of the maps elucidated that the map produced by RapidEye data (owing to its fine spatial resolution) presents more details on the spatial variation of leaf chlorophyll.

\section{Discussion}

This study demonstrates the feasibility of retrieving foliar chlorophyll using INFORM and high spatial resolution RapidEye and Sentinel-2 images. Generally, the signal dissemination from leaf to the canopy is poor (Asner, 1998; Yoder and Pettigrew-Crosby, 1995) which makes the retrieval of leaf biochemical variables from canopy spectral reflectance challenging (Darvishzadeh et al., 2008). In our study, the strong multiple scattering effects in the spruce stand with rather large vegetation fraction may have improved the needles reflectance and absorption features by a factor greater than two, particularly in red edge bands (Baret et al., 1994). Using best fit spectra, foliar chlorophyll was estimated with reasonable accuracy $\left(\mathrm{R}^{2}=0.39\right.$, $\mathrm{RMSE}=6.2$ and NRMSE $=0.31)$ from RapidEye data and Sentinel-2 data $\left(R^{2}=0.45\right.$, RMSE $=8.9$ and NRMSE $=0.36$ ) (Table 4). Further, the obtained errors were decreased when multiple solutions (Table 4) and the red-edge spectral subset for Sentinel-2 were used (Table5). Though, due to rather

\section{(RapidEye)}

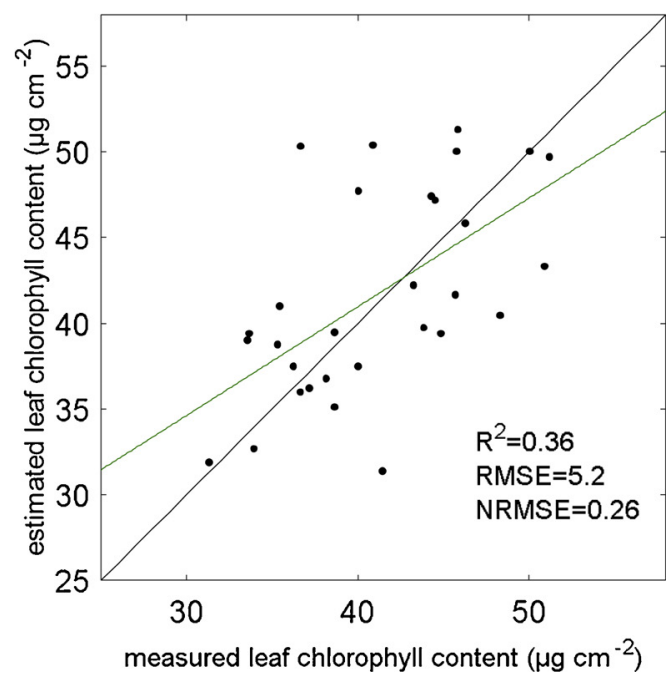

Fig. 6. Measured and retrieved leaf chlorophyll content using the mean of the best ten solutions using Sentinel-2 $(2016, \mathrm{n}=50)$ and RapidEye $(2015, \mathrm{n}=30)$ data. The black line is the 1:1 relationship and the green line present the relationship between the retrieved and measured leaf chlorophyll (For interpretation of the references to colour in this figure, the reader is referred to the web version of this article). 
Table 5

$\mathrm{R}^{2}$, RMSE and NRMSE between estimated and measured leaf chlorophyll based on spectral subsets from Sentinel-2 $(n=50)$.

\begin{tabular}{llll}
\hline Spectral subset & $\mathrm{R}^{2}$ & NRMSE \\
\hline Spectral subset A $(783 \mathrm{~nm}, 842 \mathrm{~nm}$ and $865 \mathrm{~nm}$ are excluded) & 0.26 & 9.8 \\
Spectral subset B $(490 \mathrm{~nm}, 560 \mathrm{~nm}, 665 \mathrm{~nm}, 705 \mathrm{~nm} \text {, and } 783 \mathrm{~nm})^{*}$ & 0.30 & 0.39 \\
Spectral subset C (red edge bands: $705 \mathrm{~nm}, 740 \mathrm{~nm}$, and $783 \mathrm{~nm})$ & 0.36 & 0.38 & 8.1 \\
\hline
\end{tabular}

* These spectral bands have central wavelengths close to those from RapidEye.

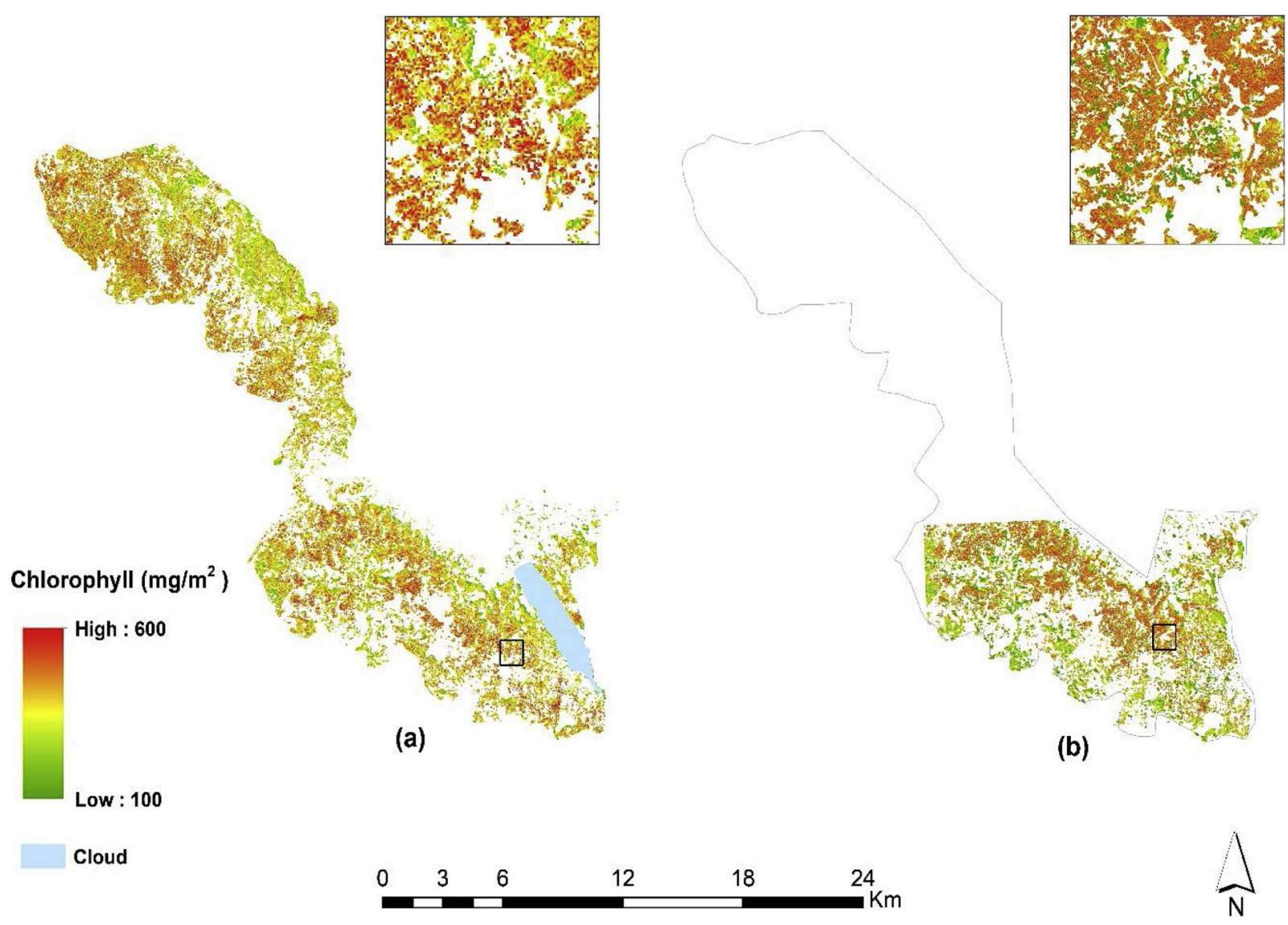

Fig. 7. Variation of foliar chlorophyll in Norway spruce stands of Bavarian Forest National Park, Germany. The maps are produced by inversion of INFORM using minimum RMSE criterion for Sentinel-2 (a) and RapidEye (b) images, respectively.

low variabilities in measured leaf chlorophyll from both field campaigns (Table 3) (coefficient of variation $=0.14$ and 0.15 for 2015 and 216 , respectively), poor retrieval accuracies were expected. The reasonable accuracies also may owe to the realistic parameterisation of the INFORM, since the suitability of an RTM for estimating leaf properties rely on a proper consideration of all the factors and processes which determine the canopy reflectance (le Maire et al., 2004). INFORM contains parameters that determine the geometrical structure of the canopy such as stand height and understory vegetation layer and employ the FLIM model to balance the undesired effects including the clumping and shadows in a three-dimensional structure (Atzberger, 2000; Schlerf and Atzberger, 2012, 2006). Such model characteristics may also have helped to decouple the reflectance of RapidEye and Sentinel-2 from canopy structural effects and leaf properties (Wang et al., 2018). However, downscaling the canopy reflectance to leaf level reflectance based on their relationship and retrieval using leaf RTMs such as PROSPECT may result in a stronger relationship between the estimated and measured leaf chlorophyll. As such, Ma et al. (2017) reported a similar error $(\mathrm{RMSE}=8.82)$ and a higher $\mathrm{R}^{2}\left(\mathrm{R}^{2}=0.59\right)$ while predicting leaf chlorophyll from Sentinel-2 data of a mixed temperate forest by downscaling the canopy reflectance to leaf reflectance based on 4-Scale and PROSPECT models. Further, the reasonable retrieval accuracy of foliar chlorophyll is attributed to the large size of LUTs in this study (500,000 records), which allowed for proper sample selection. The importance of proper sample selection when generating the LUT is emphasised by Weiss et al. (2000) as a mean to optimise the model efficiency and for better realisation of actual ecosystem condition.

The sensitivity analysis identified the model input parameters influencing forest canopy reflectance in the spectral band settings of RapidEye (475-805 nm) and Sentinel-2 (490-2190 nm) when simulated by INFORM (partly shown). The results from this analysis revealed that the canopy spectral reflectance from both sensors at $450-7750 \mathrm{~nm}$ were highly sensitive to the variation of leaf chlorophyll (not shown). This was expected as the chlorophyll absorption bands which are sensitive to pigment levels are primarily located in this region (Gitelson and Merzlyak, 1997). Among leaf parameters, leaf water content has minimal effect on the RapidEye simulated reflectance. Water sensitive features are mainly found beyond the NIR and in SWIR regions (Ollinger, 2011) which do not exist in RapidEye spectral data. Therefore this parameter was further fixed to its observed mean value, in the generation of RapidEye LUT. We observed that the simulated reflectance from the two sensors is affected by almost all stand characteristics (not shown); hence the existing knowledge from the field 
campaigns assisted for reasonable parameterisation of the model. The obtained result is in line with earlier findings by Yuan et al. (2015) and Ali et al. (2015) who demonstrated the effect of stand characteristics on INFORM simulated canopy reflectance.

In general, a close match was observed between the measured and simulated reflectance spectra of RapidEye and Sentinel-2 in the visible, and the red-edge region where the average absolute errors (AAE) were below 0.02 for both sensors (Fig. 4). However, a spectral mismatch between measured and simulated reflectance was mainly pronounced around the NIR shoulder which is most sensitive to LAI and leaf dry matter variations. These results are in agreement with earlier findings by Darvishzadeh et al. (2011) and Wang et al. (2018) who observed that using RTM, the spectral bands at NIR shoulder (around $800-850 \mathrm{~nm}$ ) have relatively high AAE. Apparently, the spectral bands from this region (800-850 $\mathrm{nm}$ ) are highly sensitive to noise or are not well modelled by RTM.

The relationship between the retrieved and measured leaf chlorophyll content utilising the best-fit spectra (minimum RMSE criterion) for Sentinel-2 data had a higher coefficient of determination with a higher error (NRMSE $=0.36$, RMSE $=8.9 \mu \mathrm{g} / \mathrm{cm}^{2}, \mathrm{R}^{2}=0.45$ ) compared to those obtained using the RapidEye data (NRMSE $=0.31$, $\mathrm{RMSE}=6.18 \mu \mathrm{g} / \mathrm{cm}^{2}$ and $\mathrm{R}^{2}=0.39$ ). These results, particularly the RMSE values obtained from different scenarios for Sentinel-2 in our study, are in agreement with that of le Maire et al. (2008) who utilised the PROSAIL model for leaf chlorophyll estimation and reached an RMSE of $8.2 \mu \mathrm{g} / \mathrm{cm}^{2}$. The retrieved accuracy for leaf chlorophyll obtained from RapidEye data in our study was comparable to those from Zarco-Tejada et al. (2001); Moorthy et al. (2008); Schlerf et al. (2010) and Croft et al. (2013) who used various remote sensing data in different forest types including conifers and obtained RMSE values of 3 to $6.9\left(\mu \mathrm{g} / \mathrm{cm}^{2}\right)$. In general, our retrieved accuracies from both sensors were higher than those obtained by Malenovský et al. (2006) who estimated forest foliar chlorophyll using hyperspectral measurements and 3D Discrete Anisotropic Radioactive Transfer (DART) model in the spruce stands. Since both RapidEye and Sentinel-2 sensors benefit from spectral bands at visible and red edge region, we believe that the lower retrieval errors obtained from RapidEye data are mainly due to its finer spatial resolution. This assumption was further confirmed when the spectral subset B of Sentinel 2, with central wavelengths similar to those from RapidEye, was selected $(490 \mathrm{~nm}, 560 \mathrm{~nm}, 665 \mathrm{~nm}, 705 \mathrm{~nm}$, and $783 \mathrm{~nm}$ ) for the inversion and returned lower retrieval accuracy in comparison to those from RapidEye (Table 5). The RapidEye high spatial resolution in combination with the availability of red-edge band makes the sensor distinctive (though expensive) from most other multispectral satellites and may contribute to the accurate leaf chlorophyll content retrieval.

To overcome and minimize the ill-posed problem a number of regularization approaches are suggested including the use of spectral subsets (Darvishzadeh et al., 2008; Marie Weiss et al., 2000), prior knowledge (Atzberger et al., 2013; Combal et al., 2002), spatial regularization (Houborg et al., 2015) and ecological constraints (Yebra and Chuvieco, 2009). The prior information obtained from the two field campaigns were considered in this study to define the range of model input parameters and avoid unlikely combinations. Further, in addition to utilising the foliar chlorophyll corresponding to the best-fitting spectra (with minimum RMSE as the cost function), we examined the mean of the first 10,50 and 100 best solutions. The use of multiple solutions showed that when the mean of the first ten best solutions is used the retrieval error of leaf chlorophyll content improved slightly for both RapidEye and Sentinel-2 data (NRMSE $=0.26$, NRMSE $=0.34$, respectively) (Table 4). These findings confirmed that utilising multiple solutions results in a more robust retrieval accuracy and lower error for the parameter of interest (Atzberger et al., 2013; Darvishzadeh et al., 2012, 2011, 2008).

When the role of spectral subsets on retrieval accuracy of foliar chlorophyll from Sentinel-2 data was evaluated, the spectral subset $\mathrm{C}$ which contained the three red edge spectral bands $(710,740,783 \mathrm{~nm})$ resulted in a relatively lower estimation error for foliar chlorophyll (Table 5). A comparable result was achieved by Delegido et al. (2011) who examined the simulated Sentinel-2 data for chlorophyll estimation and observed that the elimination of red edge spectral bands from inversion resulted in poor model prediction accuracy. In the current study, the inversion of LUT using only the three red edge bands has lowered the RMSE to $8.1 \mu \mathrm{g} / \mathrm{cm}^{2}$ (NRMSE $=0.33$ ). Nonetheless, when the other two spectral subsets which each unexploited one red edge band $(783 \mathrm{~nm}$ in subset $A$, and $740 \mathrm{~nm}$ in subset B) were used from Sentinel-2 data, the retrieval error increased indicating the importance of red edge as well as properly located spectral bands from the sensor.

For the generation of the chlorophyll maps the minimum RMSE criteria (with higher $\mathrm{R}^{2}$ ) was used for the inversion process. Overall, the chlorophyll maps from both RapidEye and Sentinel-2 represented well the variation of foliar chlorophyll in the national park. The spatial variation of foliar chlorophyll from the two maps were comparable. Though the map produced from RapidEye data presented a detailed overview of the variation of leaf chlorophyll which wasparticularly exhibited by more reddish color (higher leaf chlorophyll content). The RapidEye data due to its higher spatial resolution enabled the detection of almost individual crown cover. While the Sentinel-2 image has mixed chlorophyll from multiple crowns forming a single pixel of a larger area, by averaging the reflectance of crowns with other objects, such as understory layers and background reflectance. A more concise studying of the maps indicated that the areas exhibiting a low chlorophyll concentration are well in agreement with those found by Abdullah et al. (2018b) as areas under early-stage bark beetle infestation. Our findings emphasise the importance of multi-spectral satellite sensors with red edge spectral bands, such as Sentinel-2 and RapidEye, for regional mapping of vegetation foliar properties, particularly, chlorophyll using RTMs such as INFORM.

\section{Conclusion}

The feasibility of two multispectral satellites' imagery and the INFORM radiative transfer model for mapping leaf chlorophyll content in spruce stands of the Bavarian Forest National Park was studied. The LUT inversion method was employed for the retrieval of foliar chlorophyll. The overall results obtained in this study revealed the suitability of the INFORM model for simulating canopy reflectance from the two satellites and retrieval of leaf chlorophyll. The lowest retrieval errors, using all spectral bands of RapidEye and Sentinel-2, were obtained using the mean of the best ten solutions. Furthermore, a spectral subset that contained only the three bands from the red edge region of Sentinel-2 decreased the retrieval error and emphasised the prominence of red edge bands embedded in the Sentinel-2 data. Our results exhibit the potential of INFORM when coupled with satellite data for regional and global mapping of foliar chlorophyll in the forest ecosystem.

We note that in addition to spectral data and the model used for leaf chlorophyll estimation, uncertainties related to in situ measurements of the foliar chlorophyll is a crucial factor in determining the retrieval accuracy. In our study leaf chlorophyll was measured using hand-held chlorophyll meter and wet chemical analysis which is among the most accurate in situ methods of chlorophyll measurements. Although the measured leaf chlorophyll explained the within-plot variability, the vertical heterogeneity of leaf chlorophyll within the canopy (Gara et al., 2018) was not considered in this study. Further improvement of retrieval accuracy is expected when modulated chlorophyll (leaf chlorophyll multiplied by LAI) would be considered at the canopy level.

\section{Acknowledgements}

This work was partially funded by the European Space Agency's Innovators-III project "Remote Sensing for Essential Biodiversity Variables". We acknowledge the support from the BNFP "Data Pool 
Forestry" initiative during the field data collection. Special thanks to Prof Jörg Müller for facilitating the field activities. We are grateful to the reviewers for their thoughtful comments and suggestions that helped us to improve the manuscript.

\section{References}

Abdullah, H., Darvishzadeh, R., Skidmore, A.K., Groen, T.A., Heurich, M., 2018a. European spruce bark beetle (Ips typographus, L.) green attack affects foliar reflectance and biochemical properties. Int. J. Appl. Earth Obs. Geoinf. 64, 199-209. https://doi.org/10.1016/j.jag.2017.09.009.

Abdullah, H., Skidmore, A.K., Darvishzadeh, R., Heurich, M., 2018b. Sentinel-2 accurately maps green-attack stage of European spruce bark beetle (Ips typographus, L.) compared with Landsat-8. Remote Sens. Ecol. Conserv. https://doi.org/10.1002/ rse2.93.

Ali, A.M., Darvishzadeh, R., Skidmore, A.K., Duren, I.-V., Heiden, U., Heurich, M., Van Duren, I., Heiden, U., Heurich, M., 2015. Prospect inversion for indirect estimation of leaf dry matter content and specific leaf area. ISPRS - Int. Arch. Photogramm. Remote Sens. Spat. Inf. Sci. XL-7/W3 277-284. https://doi.org/10.5194/isprsarchives-XL-7W3-277-2015.

Ali, A.M., Darvishzadeh, R., Skidmore, A.K., Duren, I., van, Heiden, U., Heurich, M. 2016a. Estimating leaf functional traits by inversion of PROSPECT: assessing leaf dry matter content and specific leaf area in mixed mountainous forest. Int. J. Appl. Earth Obs. Geoinf. 45, 66-76. https://doi.org/10.1016/j.jag.2015.11.004.

Ali, A.M., Darvishzadeh, R., Skidmore, A.K., Van Duren, I.V.I., 2016b. Effects of canopy structural variables on retrieval of leaf dry matter content and specific leaf area from remotely sensed data. IEEE J. Sel. Top. Appl. Earth Obs. Remote Sens. 9, 898-909. https://doi.org/10.1109/JSTARS.2015.2450762.

Ali, A.M., Skidmore, A.K., Darvishzadeh, R., van Duren, I., Holzwarth, S., Mueller, J., 2016c. Retrieval of forest leaf functional traits from HySpex imagery using radiative transfer models and continuous wavelet analysis. ISPRS J. Photogramm. Remote Sens. 122, 68-80. https://doi.org/10.1016/j.isprsjprs.2016.09.015.

Ali, A.M., Darvishzadeh, R., Skidmore, A.K., 2017a. Retrieval of Specific Leaf Area from Landsat-8 Surface Reflectance Data Using Statistical and Physical Models. IEEE J. Sel. Top. Appl. Earth Obs. Remote Sens. 10. https://doi.org/10.1109/JSTARS.2017. 2690623.

Ali, A.M., Darvishzadeh, R., Skidmore, A.K., van Duren, I., 2017b. Specific leaf area estimation from leaf and canopy reflectance through optimization and validation of vegetation indices. Agric. For. Meteorol. 236, 162-174. https://doi.org/10.1016/j. agrformet.2017.01.015.

Asner, G.P., 1998. Biophysical and biochemical sources of variability in canopy reflectance. Remote Sens. Environ. 64, 234-253.

Atzberger, C., 1997. Estimating of winter wheat production through remote sensing and crop growth modeling. Akad. Abhandlungen zu den Geowissenschaften. VWF Verlag, Berlin, Germany.

Atzberger, C., 2000. Development of an invertible forest reflectance model: the INFORmodel. Buchroithner (Ed.), A Decade of Trans-European Remote Sensing Cooperation, 20th EARSeL Symposium 39-44.

Atzberger, C., Jarmer, T., Schlerf, M., Kötz, B., Werner, W., 2003. Spectroradiometric determination of wheat bio-physical variables: comparison of different empiricalstatistical approaches. Goossens, R. (Ed.), Remote Sensing in Transitions: Proceedings of the 23rd EARSeL Symposium 463-470.

Atzberger, C., Darvishzadeh, R., Schlerf, M., Le Maire, G., 2013. Suitability and adaptation of PROSAIL radiative transfer model for hyperspectral grassland studies. Remote Sens. Lett. 4, 56-65. https://doi.org/10.1080/2150704X.2012.689115.

Atzberger, C., Darvishzadeh, R., Immitzer, M., Schlerf, M., Skidmore, A., le Maire, G., 2015. Comparative analysis of different retrieval methods for mapping grassland leaf area index using airborne imaging spectroscopy. Int. J. Appl. Earth Obs. Geoinf. 43, 19-31. https://doi.org/10.1016/j.jag.2015.01.009.

Baret, F., Buis, S., 2008. Estimating Canopy Characteristics From Remote Sensing Observations: Review of Methods and Associated Problems. Adv. L. Remote Sensing, New York, USA, pp. 173-201. https://doi.org/10.1007/978-1-4020-6450-0 7.

Baret, F., Vanderbilt, V.C., Steven, M.D., Jacquemoud, S., 1994. Use of Spectral Analogy To Evaluate Canopy Reflectance Sensitivity to Leaf Optical Properties.

Bowyer, P., Danson, F.M.M., Trodd, N.M.M., 2003. Methods of sensitivity analysis in remote sensing: implications for canopy reflectance model inversion. IGARSS 2003 2003 IEEE Int. Geosci. Remote Sens. Symp. Proc. (IEEE Cat. No.03CH37477) 6, 3839-3841 https://doi.org/10.1109/IGARSS.2003.1295287.

Brix, H., 1987. Chlorophylls and carotenoids in plant material. Methods 3-5. https://doi. org/10.1016/B978-0-12-378630-2.00039-6.

Cailleret, M., Heurich, M., Bugmann, H., 2014. Reduction in browsing intensity may not compensate climate change effects on tree species composition in the Bavarian Forest National Park. For. Ecol. Manage. https://doi.org/10.1016/j.foreco.2014.05.030.

Castro-Esau, K.L., Sánchez-Azofeifa, G.A., Rivard, B., Wright, S.J., Quesada, M., 2006. Variability in leaf optical properties of mesoamerican trees and the potential for species classification. Am. J. Bot. 93, 517-530. https://doi.org/10.3732/ajb.93.4. 517.

Clevers, J.G.P.W., Gitelson, A.A., 2013. Remote estimation of crop and grass chlorophyll and nitrogen content using red-edge bands on Sentinel-2 and -3. Int. J. Appl. Earth Obs. Geoinf. 23, 344-351. https://doi.org/10.1016/j.jag.2012.10.008.

Clevers, J.G.P.W., Kooistra, L., 2012. Using hyperspectral remote sensing data for retrieving canopy chlorophyll and nitrogen content. IEEE J. Sel. Top. Appl. Earth Obs. Remote Sens. 5, 574-583. https://doi.org/10.1109/JSTARS.2011.2176468.

Clevers, J.G.P.W., Verhoef, W., 1991. Modellig and synergetic use of optical and microwave remote sening. Report 2: LAI estimation from canopy reflectance and WDVI: a sensitivity analysis with the SAIL model. BCRS Report 90-39.

Clevers, J.G.P.W., Kooistra, L., van den Brande, M.M., 2017. Using Sentinel-2 data for retrieving LAI and leaf and canopy chlorophyll content of a potato crop. Remote Sens. https://doi.org/10.3390/rs9050405.

Combal, B., Baret, F.F., Weiss, M., 2002. Improving canopy variables estimation from remote sensing data by exploiting ancillary information. Case study on sugar beet canopies. Agronomie 22, 205-215. https://doi.org/10.1051/agro:2002008.

Combal, B., Baret, F., Weiss, M., Trubuil, a., Macé, D., Pragnère, a., Myneni, R., Knyazikhin, Y., Wang, L., 2003. Retrieval of canopy biophysical variables from bidirectional reflectance using prior information to solve the ill-posed inverse problem. Remote Sens. Environ. 84, 1-15. https://doi.org/10.1016/S0034-4257(02)00035-4.

Cornelissen, J.H.C., Lavorel, S., Garnier, E., Díaz, S., Buchmann, N., Gurvich, D.E., Reich, P.B., Ter Steege, H., Morgan, H.D., Van Der Heijden, M.Ga, Pausas, J.G., Poorter, H., 2003. A handbook of protocols for standardised and easy measurement of plant functional traits worldwide. Aust. J. Bot. 51, 335-380. https://doi.org/10.1071/ BT02124.

Cortazar, B., Koydemir, H.C., Tseng, D., Feng, S., Ozcan, A., 2015. Quantification of plant chlorophyll content using Google Glass. Lab Chip 15, 1708-1716. https://doi.org/10. 1039/c4lc01279h.

Cracknell, A.P., Varotsos, Ca., Krapivin, V.F., 2009. Global Climatology and Ecodynamics. https://doi.org/10.1007/978-3-540-78209-4.

Croft, H., Chen, J.M., Zhang, Y., Simic, A., 2013. Modelling leaf chlorophyll content in broadleaf and needle leaf canopies from ground, CASI, Landsat TM 5 and MERIS reflectance data. Remote Sens. Environ. 133, 128-140. https://doi.org/10.1016/j. rse.2013.02.006.

Croft, H., Chen, J.M., Zhang, Y., Simic, A., Noland, T.L., Nesbitt, N., Arabian, J., 2015. Evaluating leaf chlorophyll content prediction from multispectral remote sensing data within a physically-based modelling framework. ISPRS J. Photogramm. Remote Sens. 102, 85-95. https://doi.org/10.1016/j.isprsjprs.2015.01.008.

Croft, H., Chen, J.M., Luo, X., Bartlett, P., Chen, B., Staebler, R.M., 2017. Leaf chlorophyll content as a proxy for leaf photosynthetic capacity. Glob. Chang. Biol. https://doi. org/10.1111/gcb.13599.

Cui, S., Zhou, K., 2017. A comparison of the predictive potential of various vegetation indices for leaf chlorophyll content. Earth Sci. Informatics 10, 169-181.

Curran, P.J., 1989. Remote sensing of foliar chemistry. Remote Sens. Environ. 30, 271-278.

Dahms, T., Seissiger, S., Borg, E., Vajen, H., Fichtelmann, B., Conrad, C., 2016. Important Variables of a RapidEye Time Series for Modelling Biophysical Parameters of Winter Wheat. Photogramm. - Fernerkundung - Geoinf. https://doi.org/10.1127/pfg/2016/ 0303.

Darvishzadeh, R., Skidmore, A., Schlerf, M., Atzberger, C., 2008. Inversion of a radiative transfer model for estimating vegetation LAI and chlorophyll in a heterogeneous grassland. Remote Sens. Environ. 112, 2592-2604. https://doi.org/10.1016/j.rse. 2007.12.003.

Darvishzadeh, R., Atzberger, C., Skidmore, A., Schlerf, M., 2011. Mapping grassland leaf area index with airborne hyperspectral imagery: a comparison study of statistical approaches and inversion of radiative transfer models. ISPRS J. Photogramm. Remote Sens. 66, 894-906. https://doi.org/10.1016/j.isprsjprs.2011.09.013.

Darvishzadeh, R., Matkan, A.A., Dashti Ahangar, A., 2012. Inversion of a radiative transfer model for estimation of rice canopy chlorophyll content using a lookup-table approach. IEEE J. Sel. Top. Appl. Earth Obs. Remote Sens. 5, 1222-1230. https://doi. org/10.1109/JSTARS.2012.2186118.

Dawson, T.P., Curran, P.J., North, P.R.J., Plummer, S.E., 1999. The propagation of foliar biochemical absorption features in forest canopy reflectance: a theoretical analysis. Remote Sens. Environ. 67, 147-159.

Delegido, J., Verrelst, J., Alonso, L., Moreno, J., 2011. Evaluation of sentinel-2 red-edge bands for empirical estimation of green LAI and chlorophyll content. Sensors. https:// doi.org/10.3390/s110707063.

Delegido, J., Van Wittenberghe, S., Verrelst, J., Ortiz, V., Veroustraete, F., Valcke, R., Samson, R., Rivera, J.P., Tenjo, C., Moreno, J., 2014. Chlorophyll content mapping of urban vegetation in the city of Valencia based on the hyperspectral NAOC index. Ecol. Indic. 40, 34-42. https://doi.org/10.1016/j.ecolind.2014.01.002.

Demarez, V., Gastellu-Etchegorry, J.P., 2000. A modeling approach for studying forest chlorophyll content. Remote Sens. Environ. 71, 226-238. https://doi.org/10.1016/ S0034-4257(99)00089-9.

Fourty, T., Baret, F., Jacquemoud, S., Schmuck, G., Verdebout, J., 1996. Leaf optical properties with explicit description of its biochemical composition: direct and inverse problems. Remote Sens. Environ. 56, 104-117.

Gara, T.W., Darvishzadeh, R., Skidmore, A.K., Wang, T., 2018. Impact of vertical canopy position on leaf spectral properties and traits across multiple species. Remote Sens. 10. https://doi.org/10.3390/rs10020346.

Garnier, E., Lavorel, S., Ansquer, P., Castro, H., Cruz, P., Dolezal, J., Eriksson, O., Fortunel, C., Freitas, H., Golodets, C., Grigulis, K., Jouany, C., Kazakou, E., Kigel, J., Kleyer, M., Lehsten, V., Leps, J., Meier, T., Pakeman, R., Papadimitriou, M., Papanastasis, V.P., Quested, H., Quetier, F., Robson, M., Roumet, C., Rusch, G., Skarpe, C., Sternberg, M., Theau, J.-P., Thebault, A., Vile, D., Zarovali, M.P., 2007. Assessing the effects of land-use change on plant traits, communities and ecosystem functioning in grasslands: a standardized methodology and lessons from an application to 11 European Sites. Ann. Bot. 99, 967-985. https://doi.org/10.1093/aob/ mcl215.

Gitelson, A.A., Merzlyak, M.N., 1997. Remote estimation of chlorophyll content in higher plant leaves. Int. J. Remote Sens. V18, 2691-2697.

Gitelson, Aa., Merzlyak, M.N., Lichtenthaler, H.K., 1996. Detection of red edge position and chlorophyll content by reflectance measurements near $700 \mathrm{~nm}$. J. Plant Physiol. 148, 501-508. https://doi.org/10.1016/S0176-1617(96)80285-9. 
Gitelson, Aa., Keydan, G.P., Merzlyak, M.N., 2006. Three-band model for noninvasive estimation of chlorophyll, carotenoids, and anthocyanin contents in higher plant leaves. Geophys. Res. Lett. 33, 1-6. https://doi.org/10.1029/2006GL026457.

Haboudane, D., Miller, J.R., Tremblay, N., Zarco-Tejada, P.J., Dextraze, L., 2002. Integrated narrow-band vegetation indices for prediction of crop chlorophyll content for application to precision agriculture. Remote Sens. Environ. 81, 416-426.

Hernández-Clemente, R., Navarro-Cerrillo, R.M., Zarco-Tejada, P.J., 2012. Carotenoid content estimation in a heterogeneous conifer forest using narrow-band indices and PROSPECT + DART simulations. Remote Sens. Environ. 127, 298-315. https://doi. org/10.1016/j.rse.2012.09.014.

Heurich, M., Ochs, T., Andresen, T., Schneider, T., 2010. Object-orientated image analysis for the semi-automatic detection of dead trees following a spruce bark beetle (Ips typographus) outbreak. Eur. J. For. Res. 129, 313-324. https://doi.org/10.1007/ s10342-009-0331-1.

Homolová, L., Malenovský, Z., Clevers, J.G.P.W., García-Santos, G., Schaepman, M.E., 2013. Review of optical-based remote sensing for plant trait mapping. Ecol. Complex. 15, 1-16. https://doi.org/10.1016/j.ecocom.2013.06.003.

Houborg, R., McCabe, M.F., 2016. Adapting a regularized canopy reflectance model (REGFLEC) for the retrieval challenges of dryland agricultural systems. Remote Sens. Environ. https://doi.org/10.1016/j.rse.2016.08.017.

Houborg, R., Anderson, M., Daughtry, C., 2009. Utility of an image-based canopy reflectance modeling tool for remote estimation of LAI and leaf chlorophyll content at the field scale. Remote Sens. Environ. 113, 259-274.

Houborg, R., McCabe, M., Cescatti, A., Gao, F., Schull, M., Gitelson, A., 2015. Joint leaf chlorophyll content and leaf area index retrieval from Landsat data using a regularized model inversion system (REGFLEC). Remote Sens. Environ. 159, 203-221. https://doi.org/10.1016/j.rse.2014.12.008.

Inoue, Y., Guérif, M., Baret, F., Skidmore, A., Gitelson, A., Schlerf, M., Darvishzadeh, R., Olioso, A., 2016. Simple and robust methods for remote sensing of canopy chlorophyll content: a comparative analysis of hyperspectral data for different types of vegetation. Plant Cell Environ. 39, 2609-2623. https://doi.org/10.1111/pce.12815.

Jacquemoud, S., Baret, F., 1990. PROSPECT: a model of leaf optical properties spectra. Remote Sens. Environ. 34, 75-91.

Jacquemoud, S., Ustin, S.L., Verdebout, J., Schmuck, G., Andreoli, G., Hosgood, B., 1996. Estimating leaf biochemistry using the PROSPECT leaf optical properties model. Remote Sens. Environ. 56, 194-202. https://doi.org/10.1016/0034-4257(95) 00238-3.

Jiao, Q., Zhang, B., Liu, J., Liu, L., 2014. A novel two-step method for winter wheat-leaf chlorophyll content estimation using a hyperspectral vegetation index. Int. J. Remote Sens. 35, 7363-7375. https://doi.org/10.1080/2150704X.2014.968681.

Kimes, D.S., Knyazikhin, Y., Privette, J.L., Abuelgasim, A.A., Gao, F., 2000. Inversion methods for physically-based models. Remote Sens. Rev. 18, 381-439.

Knyazikhin, Y., Martonchik, J.V., Myneni, R.B., Diner, D.J., Running, S.W., 1998. Synergistic algorithm for estimating vegetation canopy leaf area index and fraction of absorbed photosynthetically active radiation from MODIS and MISR data. J. Geophys. Res. D Atmos. 103 (32), 232-257 275.

Kokaly, R.F., Asner, G.P., Ollinger, S.V., Martin, M.E., Wessman, C.A., 2009. Characterizing canopy biochemistry from imaging spectroscopy and its application to ecosystem studies. Remote Sens. Environ. 113. https://doi.org/10.1016/j.rse.2008. 10.018 .

Kooistra, L., Clevers, J.G.P.W., 2016. Estimating potato leaf chlorophyll content using ratio vegetation indices. Remote Sens. Lett. https://doi.org/10.1080/2150704X. 2016.1171925

Lausch, A., Heurich, M., Fahse, L., 2013. Spatio-temporal infestation patterns of Ips typographus (L.) in the Bavarian Forest National Park. Germany. Ecol. Indic 31, 73-81. https://doi.org/10.1016/j.ecolind.2012.07.026.

Lavergne, T., Kaminski, T., Pinty, B., Taberner, M., Gobron, N., Verstraete, M.M. Vossbeck, M., Widlowski, J.-L., Giering, R., 2007. Application to MISR land products of an RPV model inversion package using adjoint and Hessian codes. Remote Sens. Environ. 107, 362-375.

Lavorel, S., Grigulis, K., Lamarque, P., Colace, M.-P., Garden, D., Girel, J., Pellet, G., Douzet, R., 2011. Using plant functional traits to understand the landscape distribution of multiple ecosystem services. J. Ecol. 99, 135-147. https://doi.org/10. 1111/j.1365-2745.2010.01753.x.

le Maire, G., Francois, C., Dufrene, E., 2004. Towards universal broad leaf chlorophyll indices using PROSPECT simulated database and hyperspectral reflectance measurements. Remote Sens. Environ. 89, 1-28.

le Maire, G., François, C., Soudani, K., Berveiller, D., Pontailler, J.Y., Bréda, N., Genet, H., Davi, H., Dufrêne, E., 2008. Calibration and validation of hyperspectral indices for the estimation of broadleaved forest leaf chlorophyll content, leaf mass per area, leaf area index and leaf canopy biomass. Remote Sens. Environ. 112, 3846-3864. https:// doi.org/10.1016/j.rse.2008.06.005.

Liang, S., 2004. Quantitative Remote Sensing of Land Surfaces. Wiley Praxis series in Remote Sensing. Wiley \& Sons, Hoboken etc.

Liang, L., Qin, Z., Zhao, S., Di, L., Zhang, C., Deng, M., Lin, H., Zhang, L., Wang, L., Liu, Z., 2016. Estimating crop chlorophyll content with hyperspectral vegetation indices and the hybrid inversion method. Int. J. Remote Sens. 37, 2923-2949. https://doi.org/10. 1080/01431161.2016.1186850.

Lichtenthaler, H.K., 1987. Chlorophylls and carotenoids: pigments of photosynthetic biomembranes. Methods Enzym. 148, 350-382.

Lichtenthaler, H.K., Buschmann, C., 2001. Chlorophylls and carotenoids: measurement and characterization by UV-VIS. Curr. Protoc. Food Anal. Chem. F4.3 (1-F4), 1-8. https://doi.org/10.1002/0471142913.

LI-COR, 1992. LAI-2000 Plant Canopy Analyzer Instruction Manual.

Ma, Q., Chen, J.M., Li, Y., Croft, H., Luo, X., Zheng, T., Zamaria, S., 2017. Leaf chlorophyll content estimation from sentinel-2 MSI data. 2017 IEEE International Geoscience and
Remote Sensing Symposium (IGARSS) 2915-2918. https://doi.org/10.1109/IGARSS. 2017.8127608

Malenovský, Z., Ufer, C., Lhotáková, Z., Clevers, J.G.P.W., Schaepman, M.E., Albrechtová, J., Cudlín, P., Malenovský Z Lhotáková, Z., Clevers, J.G.P.W., Schaepman, M.E., Albrechtová, J., P Cudlín, C.U., 2006. A new hyperspectral index for chlorophyll estimation of a forest canopy: area under curve normalised to maximal band depth between 650-725 nm. EARSeL eProceedings 5, 161-172.

Meroni, M., Colombo, R., Panigada, C., 2004. Inversion of a radiative transfer model with hyperspectral observations for LAI mapping in poplar plantations. Remote Sens. Environ. 92, 195-206.

Mirzaie, M., Darvishzadeh, R., Shakiba, A., Matkan, A.A., Atzberger, C., Skidmore, A., 2014. Comparative analysis of different uni- and multi-variate methods for estimation of vegetation water content using hyper-spectral measurements. Int. J. Appl. Earth Obs. Geoinf. 26, 1-11.

Moorthy, I., Miller, J.R., Noland, T.L., 2008. Estimating chlorophyll concentration in conifer needles with hyperspectral data: an assessment at the needle and canopy level. Remote Sens. Environ. 112, 2824-2838. https://doi.org/10.1016/j.rse.2008. 01.013.

Navarro-Cerrilloa, R.M., Trujillo, J., de la Orden, M.S., Hernandez-Clemente, R.R.R. 2014. Hyperspectral and multispectral satellite sensors for mapping chlorophyll content in a Mediterranean Pinus sylvestris L. Plantation. Int. J. Appl. Earth Obs. Geoinf. 26, 88-96. https://doi.org/10.1016/j.jag.2013.06.001.

Neinavaz, E., Skidmore, A.K., Darvishzadeh, R., Groen, T.A., 2017. Retrieving vegetation canopy water content from hyperspectral thermal measurements. Agric. For. Meteorol. 247, 365-375. https://doi.org/10.1016/j.agrformet.2017.08.020.

Ollinger, S.V., 2011. Sources of variability in canopy reflectance and the convergent properties of plants. New Phytol. 189, 375-394. https://doi.org/10.1111/j.14698137.2010.03536.x.

Orwin, K.H., Buckland, S.M., Johnson, D., Turner, B.L., Smart, S., Oakley, S., Bardgett, R.D., 2010. Linkages of plant traits to soil properties and the functioning of temperate grassland. J. Ecol. 98, 1074-1083. https://doi.org/10.1111/j.1365-2745.2010. 01679.x.

Pastor-Guzman, J., Atkinson, P.M., Dash, J., Rioja-Nieto, R., 2015. Spatiotemporal variation in mangrove chlorophyll concentration using Landsat 8. Remote Sens. (Basel). https://doi.org/10.3390/rs71114530.

Planet, 2016. RAPIDEYE ${ }^{\mathrm{TM}}$ IMAGERY PRODUCT SPECIFICATIONS. https://www.planet. com/products/satellite-imagery/files/160625-RapidEyeImage-ProductSpecifications.pdf.

Richter, R., Schläpfer, D., 2018. Atmospheric / Topographic Correction for Airborne Imagery.

Rivera, J.P., Verrelst, J., Delegido, J., Veroustraete, F., Moreno, J., 2014. On the semiautomatic retrieval of biophysical parameters based on spectral index optimization. Remote Sens. 6, 4927-4951. https://doi.org/10.3390/rs6064927.

Rosema, A., Verhoef, W., Noorbergen, H., Borgesius, J.J., 1992. A new forest light interaction model in support of forest monitoring. Remote Sens. Environ. 42, 23-41. https://doi.org/10.1016/0034-4257(92)90065-R.

Schlerf, M., Atzberger, C., 2006. Inversion of a forest reflectance model to estimate structural canopy variables from hyperspectral remote sensing data. Remote Sens. Environ. 100, 281-294.

Schlerf, M., Atzberger, C., 2012. Vegetation structure retrieval in Beech and spruce forests using spectrodirectional satellite data. IEEE J. Sel. Top. Appl. Earth Obs. Remote Sens. 5, 8-17. https://doi.org/10.1109/JSTARS.2012.2184268.

Schlerf, M., Atzberger, C., Hill, J., Buddenbaum, H., Werner, W., Schueler, G., 2010. Retrieval of chlorophyll and nitrogen in Norway spruce (Picea abies L. Karst.) using imaging spectroscopy. Int. J. Appl. Earth Obs. Geoinf. 12, 17-26. https://doi.org/10. 1016/j.jag.2009.08.006.

Shang, J., Liu, J., Ma, B., Zhao, T., Jiao, X., Geng, X., Huffman, T., Kovacs, J.M., Walters, D., 2015. Mapping spatial variability of crop growth conditions using RapidEye data in Northern Ontario, Canada. Remote Sens. Environ. 168, 113-125. https://doi.org/ 10.1016/j.rse.2015.06.024.

Sievering, H., Fernandez, I., Lee, J., Horn, J., Rustad, L., 2000. Forest canopy uptake of atmospheric nitrogen deposition at eastern U.S. Conifer sites: carbon storage implications? Global Biogeochem. Cycles. https://doi.org/10.1029/2000GB001250.

Silveyra Gonzalez, R., Latifi, H., Weinacker, H., Dees, M., Koch, B., Heurich, M., 2018. Integrating LiDAR and high-resolution imagery for object-based mapping of forest habitats in a heterogeneous temperate forest landscape. Int. J. Remote Sens. 39, 8859-8884. https://doi.org/10.1080/01431161.2018.1500071.

Sims, Da., Gamon, Ja., 2002. Relationships between leaf pigment content and spectral reflectance across a wide range of species, leaf structures and developmental stages. Remote Sens. Environ. 81, 337-354. https://doi.org/10.1016/S0034-4257(02) 00010-X.

Skidmore, A.K., 2002. Environmental Modelling With GIS and Remote Sensing.

Skidmore, A.K., Pettorelli, N., Coops, N.C., Geller, G.N., Hansen, M., Lucas, R., Mücher, C.A., O'Connor, B., Paganini, M., Pereira, H.M., Schaepman, M.E., Turner, W., Wang, T., Wegmann, M., 2015. Environmental science: agree on biodiversity metrics to track from space. Nature 523, 403-405, https://doi.org/10.1038/523403a.

Sun, H., Zheng, T., Liu, N., Cheng, M., Li, M., Zhang, Q., 2018. Vertical distribution of chlorophyll in potato plants based on hyperspectral imaging. Nongye Gongcheng Xuebao/Transactions Chinese Soc. Agric. Eng. 34, 149-156. https://doi.org/10. 11975/j.issn.1002-6819.2018.01.020.

Tang, S., Chen, J.M., Zhu, Q., Li, X., Chen, M., Sun, R., Zhou, Y., Deng, F., Xie, D., 2006. LAI inversion algorithm based on directional reflectance kernels. J. Environ. Manage. 58 doi: 10.101.

Ullah, S., 2013. Thermal Plants: Characterizing Vegetation Parameters Using Mid to Thermal Infrared Hyperspectral Remote Sensing. https://doi.org/978-90-6164-3579. . 
Verhoef, W., 1984. Light scattering by leaf layers with application to canopy reflectance modeling: the SAIL model. Remote Sens. Environ. 16, 125-141.

Verhoef, W., 1985. Earth observation modeling based on layer scattering matrices. Remote Sens. Environ. 17, 165-178.

Verrelst, J., Camps-Valls, G., Muñoz-Marí, Jordi, Rivera, J.P., Veroustraete, F., Clevers, J.G.P.W., Moreno, J., 2015. Optical remote sensing and the retrieval of terrestrial vegetation bio-geophysical properties-a review. ISPRS J. Photogramm. Remote Sens. 108, 273-290. https://doi.org/10.1016/j.isprsjprs.2015.05.005.

Wang, Z., Skidmore, A.K., Darvishzadeh, R., Heiden, U., Heurich, M., Wang, T., 2015. Leaf nitrogen content indirectly estimated by leaf traits derived from the PROSPECT model. IEEE J. Sel. Top. Appl. Earth Obs. Remote Sens. 8, 3172-3182. https://doi. org/10.1109/JSTARS.2015.2422734.

Wang, Z., Skidmore, A.K., Darvishzadeh, R., Wang, T., 2018. Mapping forest canopy nitrogen content by inversion of coupled leaf-canopy radiative transfer models from airborne hyperspectral imagery. Agric. For. Meteorol. 253-254. https://doi.org/10 1016/j.agrformet.2018.02.010.

Weiss, M., Baret, F., Myneni, R.B., Pragnere, A., Knyazikhin, Y., 2000. Investigation of a model inversion technique to estimate canopy biophysical variables from spectral and directional reflectance data. Agronomie 20, 3-22. https://doi.org/10.1051/ agro:2000105.

Widlowski, J.L., Mio, C., Disney, M., Adams, J., Andredakis, I., Atzberger, C., Brennan, J., Busetto, L., Chelle, M., Ceccherini, G., Colombo, R., Côté, J.F., Eenmäe, A., Essery, R., Gastellu-Etchegorry, J.P., Gobron, N., Grau, E., Haverd, V., Homolová, L., Huang, H., Hunt, L., Kobayashi, H., Koetz, B., Kuusk, A., Kuusk, J., Lang, M., Lewis, P.E., Lovell, J.L., Malenovský, Z., Meroni, M., Morsdorf, F., Mõttus, M., Ni-Meister, W., Pinty, B., Rautiainen, M., Schlerf, M., Somers, B., Stuckens, J., Verstraete, M.M., Yang, W.,

Zhao, F., Zenone, T., 2015. The fourth phase of the radiative transfer model intercomparison (RAMI) exercise: Actual canopy scenarios and conformity testing. Remote Sens. Environ. https://doi.org/10.1016/j.rse.2015.08.016.
Yang, G.J., Zhao, C.J., Liu, Q., Huang, W.J., Wang, J.H., 2011. Inversion of a radiative transfer model for estimating forest LAI from multisource and multiangular optical remote sensing data. IEEE Trans. Geosci. Remote Sens. 49, 988-1000 https://doi.org/ Doi 10.1109/Tgrs.2010.2071416.

Yebra, M., Chuvieco, E., 2009. Linking ecological information and radiative transfer models to estimate fuel moisture content in the Mediterranean region of Spain: Solving the ill-posed inverse problem. Remote Sens. Environ. https://doi.org/10. 1016/j.rse.2009.07.001.

Yoder, B.J., Pettigrew-Crosby, R.E., 1995. Predicting nitrogen and chlorophyll content and concentrations from reflectance spectra $(400-2500 \mathrm{~nm})$ at leaf and canopy scales. Remote Sens. Environ. 53, 199-211. https://doi.org/10.1016/0034-4257(95) 00135-N.

Yuan, H., Ma, R., Atzberger, C., Li, F., Loiselle, S., Luo, J., 2015. Estimating forest fAPAR from multispectral Landsat-8 data using the invertible forest reflectance model INFORM. Remote Sens. 7, 7425-7446. https://doi.org/10.3390/rs70607425.

Zarco-Tejada, P.J., Miller, J.R., Noland, T.L., Mohammed, G.H., Sampson, P.H., 2001. Scaling-up and model inversion methods with narrow-band optical indices for chlorophyll content estimation in closed forest canopies with hyperspectral data. IEEE Trans. Geosci. Remote Sens. 39, 1491-1507.

Zarco-Tejada, P.J., Miller, J.R., Mohammed, G.H., Noland, T.L., Sampson, P.H., 2002 Vegetation stress detection through chlorophyll $\mathrm{a}+\mathrm{b}$ estimation and fluorescence effects on hyperspectral imagery. J. Environ. Qual. 31, 1433-1441.

Zhu, X., Wang, T., Skidmore, A.K., Darvishzadeh, R., Niemann, K.O., Liu, J., 2017. Canopy leaf water content estimated using terrestrial LiDAR. Agric. For. Meteorol. 232, 152-162. https://doi.org/10.1016/j.agrformet.2016.08.016.

Zhu, X., Skidmore, A.K., Darvishzadeh, R., Wang, T., 2019. Estimation of forest leaf water content through inversion of a radiative transfer model from LiDAR and hyperspectral data. Int. J. Appl. Earth Obs. Geoinf. 74, 120-129. https://doi.org/10.1016/J. JAG.2018.09.008. 